OPEN ACCESS

Edited by:

Marie-Eve Tremblay, Laval University, Canada

Reviewed by:

Francesco Ferrini,

University of Turin, Italy

Yuriko Iwakura,

Niigata University, Japan

*Correspondence:

Mark C. Bellingham

mark.bellingham@uq.edu.au

Specialty section

This article was submitted to Cellular Neurophysiology,

a section of the journal

Frontiers in Cellular Neuroscience

Received: 21 May 2019

Accepted: 29 July 2019

Published: 13 August 2019

Citation:

Pradhan J, Noakes $P G$ and Bellingham MC (2019) The Role of Altered BDNF/TrkB Signaling

in Amyotrophic Lateral Sclerosis.

Front. Cell. Neurosci. 13:368.

doi: 10.3389/fncel.2019.00368

\section{The Role of Altered BDNF/TrkB Signaling in Amyotrophic Lateral Sclerosis}

\author{
Jonu Pradhan', Peter G. Noakes ${ }^{1,2}$ and Mark C. Bellingham ${ }^{1 *}$ \\ 'Faculty of Medicine, School of Biomedical Sciences, The University of Queensland, Brisbane, QLD, Australia, ${ }^{2}$ Queensland \\ Brain Institute, The University of Queensland, Brisbane, QLD, Australia
}

Brain derived neurotrophic factor (BDNF) is well recognized for its neuroprotective functions, via activation of its high affinity receptor, tropomysin related kinase $B$ (TrkB). In addition, BDNF/TrkB neuroprotective functions can also be elicited indirectly via activation of adenosine $2 A$ receptors $\left(A_{2 a} R s\right)$, which in turn transactivates TrkB. Evidence suggests that alterations in BDNF/TrkB, including TrkB transactivation by $\mathrm{A}_{2 a} \mathrm{Rs}$, can occur in several neurodegenerative diseases, including amyotrophic lateral sclerosis (ALS). Although enhancing BDNF has been a major goal for protection of dying motor neurons (MNs), this has not been successful. Indeed, there is emerging in vitro and in vivo evidence suggesting that an upregulation of BDNF/TrkB can cause detrimental effects on MNs, making them more vulnerable to pathophysiological insults. For example, in ALS, early synaptic hyper-excitability of MNs is thought to enhance BDNF-mediated signaling, thereby causing glutamate excitotoxicity, and ultimately MN death. Moreover, direct inhibition of TrkB and $\mathrm{A}_{2 a} \mathrm{Rs}$ has been shown to protect MNs from these pathophysiological insults, suggesting that modulation of BDNF/TrkB and/or $A_{2 a} R s$ receptors may be important in early disease pathogenesis in ALS. This review highlights the relevance of pathophysiological actions of BDNF/TrkB under certain circumstances, so that manipulation of BDNF/TrkB and $\mathrm{A}_{2 a}$ Rs may give rise to alternate neuroprotective therapeutic strategies in the treatment of neural diseases such as ALS.

Keywords: BDNF, TrkB receptors, $A_{2 a} R$, motor neurons, ALS, MND

\section{INTRODUCTION}

Amyotrophic lateral sclerosis (ALS), the most common form of motor neuron disease (MND), is a fatal adult onset neurodegenerative disease resulting in progressive and preferential degeneration and death of upper motor neurons (UMNs, corticospinal neurons) of the motor cortex, and alpha lower motor neurons (LMNs) of the brain stem and the spinal cord (Cleveland and Rothstein, 2001; Turner et al., 2013). The incidence of ALS is 1.7 per 100,000 people each year (Pasinelli and Brown, 2006; Marin et al., 2017; Sandstedt et al., 2018). Only 10\% of all ALS cases exhibit familial inheritance (fALS) (Turner et al., 2013) while the remaining 90\% are sporadic (sALS). Mutations in the gene encoding $\mathrm{Cu} / \mathrm{Zn}$ superoxide dismutase 1 (SOD1) were the first to be identified as a primary ALS mutation (Rosen et al., 1993) and have been also the most characterized, with several widely used mouse models of SOD1 mutations (Gurney et al., 1994). Overall, SOD1 mutations account for 
$20 \%$ of fALS and $1-2 \%$ of sALS, with more than 180 mutations identified within the SOD1 gene (Hayashi et al., 2016).

Despite decades of research, the pathogenic mechanism underlying death of UMNs and LMNs is still unclear. Numerous etiologies have been proposed, including oxidative stress, mitochondrial dysfunction, protein aggregation, RNA processing, autophagy, and glutamate excitotoxicity (Chico et al., 2017). Glutamate excitotoxicity, the focus of this review, results from a disruption of the finely tuned cellular response to input stimuli, resulting in excessive glutamate release from the pre-synaptic neuron, delayed clearance from the synaptic cleft or increased responsiveness by glutamate receptors postsynaptically (Rothstein et al., 1992; Hayashi et al., 2016). Excessive release of glutamate induced by $\mathrm{Ca}^{2+}$ dysregulation within the pre-synaptic compartment (Van Den Bosch et al., 2006; King et al., 2016), causes a prolonged state of activation of postsynaptic glutamate N-methyl-D-aspartate (NMDA) and alpha-amino-3hydroxy-5-methyl-4-isoxazole propionate (AMPA) receptors. In addition to this, the $\mathrm{Ca}^{2+}$ buffering capacity of MNs in ALS is weakened at an early age, with impairment of the $\mathrm{Ca}^{2+}$ ATPase and $\mathrm{Na}^{+} / \mathrm{Ca}^{2+}$ exchanger adding to the cytoplasmic $\mathrm{Ca}^{2+}$ load (DeJesus-Hernandez et al., 2011; Sirabella et al., 2018). Enhanced post-synaptic glutamate receptor activation is physiologically observed as synaptic hyper-activity of upper and lower MNs (van Zundert et al., 2008; Fogarty et al., 2015). Hyper-activity also raises the level of intracellular $\mathrm{Ca}^{2+}$ within the post-synaptic $\mathrm{MN}$, potentially creating a toxic intracellular environment that can cause cell death (Le Masson et al., 2014; Figure 1).

Amyotrophic lateral sclerosis progresses relentlessly and, without effective intervention, $50 \%$ of the patients die within 3 to 5 years post-diagnosis, due to loss of their respiratory MNs (i.e., respiratory failure) (Brown and Al-Chalabi, 2017). The only FDA approved treatments so far are riluzole, which acts to reduce the release of glutamate and hence lower neuronal excitotoxicity (Bellingham, 2013b), and edaravone, an anti-oxidant compound. Unfortunately, riluzole only marginally enhances survival by a few months (Bensimon et al., 1994; Fang et al., 2018). In 2017 after more than 20 years, a second drug Radicava (edaravone) has been FDA approved to treat ALS; thus far, edaravone has also only been shown to slow the rate of clinical progression in ALS (Abe et al., 2014). This slow development of new treatments highlights the need to better understand the cellular and molecular mechanisms of ALS, so as to develop effective combination therapies to ameliorate this multi-factorial disease.

In addition to neuronal hyper-excitability in neuromotor circuits in ALS, the level of neuronal activity strongly influences the modification of neuronal circuits in the developing CNS, by stabilizing and strengthening coincident inputs and refining/removing weaker inputs (Goodman and Shatz, 1993; Stevens et al., 2007; Kutsarova et al., 2016). This developmental plasticity initially depends on the release of neurotransmitters from the pre-synaptic neuron (Andreae and Burrone, 2018), and thus factors that increase pre-synaptic activity will also increase synaptic plasticity. In ALS, upper and lower MNs in animal models of ALS have been shown to exhibit synaptic hyper-activity (van Zundert et al., 2008; Fogarty et al., 2015). In the case of lower MNs, hyperactivity of upper MNs could in turn result in enhanced glutamate release from their nerve terminal boutons at their synapses with lower MNs (Figure 1). Excessive release of glutamate from these pre-synaptic inputs onto lower MNs could lead to their death by excitotoxicity (King et al., 2016). Similar mechanisms may also operate for excitable synaptic connections made onto upper and lower MNs from other pre-motor excitatory inputs (van Zundert et al., 2008). To complicate matters, changes in neuronal circuit activity outside of what is considered a "normal physiological range" (i.e., "hyper-excitability;" Bae et al., 2013), can induce compensatory effects termed "synaptic homeostasis" (Turrigiano, 2012). For example, in SOD $1^{G 93 A}$ ALS model mice, while upper MNs have been shown to be hyper-active prior to their death, these neurons display reductions in dendritic length and spine density, suggesting a homeostatic response to heightened pre-synaptic activity (Fogarty et al., 2015; Saba et al., 2016). Alternatively, these morphological reductions may simply reflect the stressed state of the neurons as it progresses to death (Fogarty et al., 2016). Together these observations suggest that abnormal neuronal activity and death of upper and lower MNs in ALS are directly linked.

What might be the mechanism(s) that links abnormal neuronal activity to neuronal death? One proposed mechanism is the activity-dependent synthesis and release of neurotrophins (McAllister et al., 1996; Du et al., 2003; Cunha et al., 2010). Neurotrophins are secreted proteins and potent regulators of neuronal development, survival, neurogenesis and synaptic plasticity (Huang and Reichardt, 2001). They have long been targeted as prospective therapeutic agents for the treatment of neurodegenerative disorders, including ALS. The neurotrophin family constitutes nerve growth factor (NGF), brain derived neurotrophic factor (BDNF), neurotrophin-3 (NT-3), and neurotrophin-4/5 (NT-4/5). Amongst these, BDNF is abundantly expressed in the developing and adult nervous system (Murer et al., 2001) and has been extensively studied for its roles in neuronal survival (e.g., MNs) (Ringholz et al., 2005; Pansarasa et al., 2018), along with its ability to increase the release of glutamate at glutamatergic synapses (Rao and Finkbeiner, 2007; Mattson, 2008). Given these proposed roles for BDNF, namely its neurotrophic and possible neurotoxic roles, it becomes apparent that regulation of BDNF could open up new therapeutic strategies in the treatment of neurodegenerative disorders. This review focuses on the biology of BDNF and its proposed neurotrophic and neurotoxic roles in the pathogenesis and treatment of ALS.

\section{BIOLOGY OF BDNF: FROM SYNTHESIS TO SECRETION}

Brain derived neurotrophic factor is a member of the family of growth factors and was initially purified from pig brain (Barde et al., 1982). The expression of BDNF in human, rat and mouse is encoded by a single BDNF gene, whose transcription is regulated by several promoters (Sasi et al., 2017). The human BDNF gene consists of eleven $5^{\prime}$ untranslated (UTR) exons, compared to 9 exons found in rodents (rats and mice), and only one $3^{\prime}$ coding exon. These exons initiate transcription at 


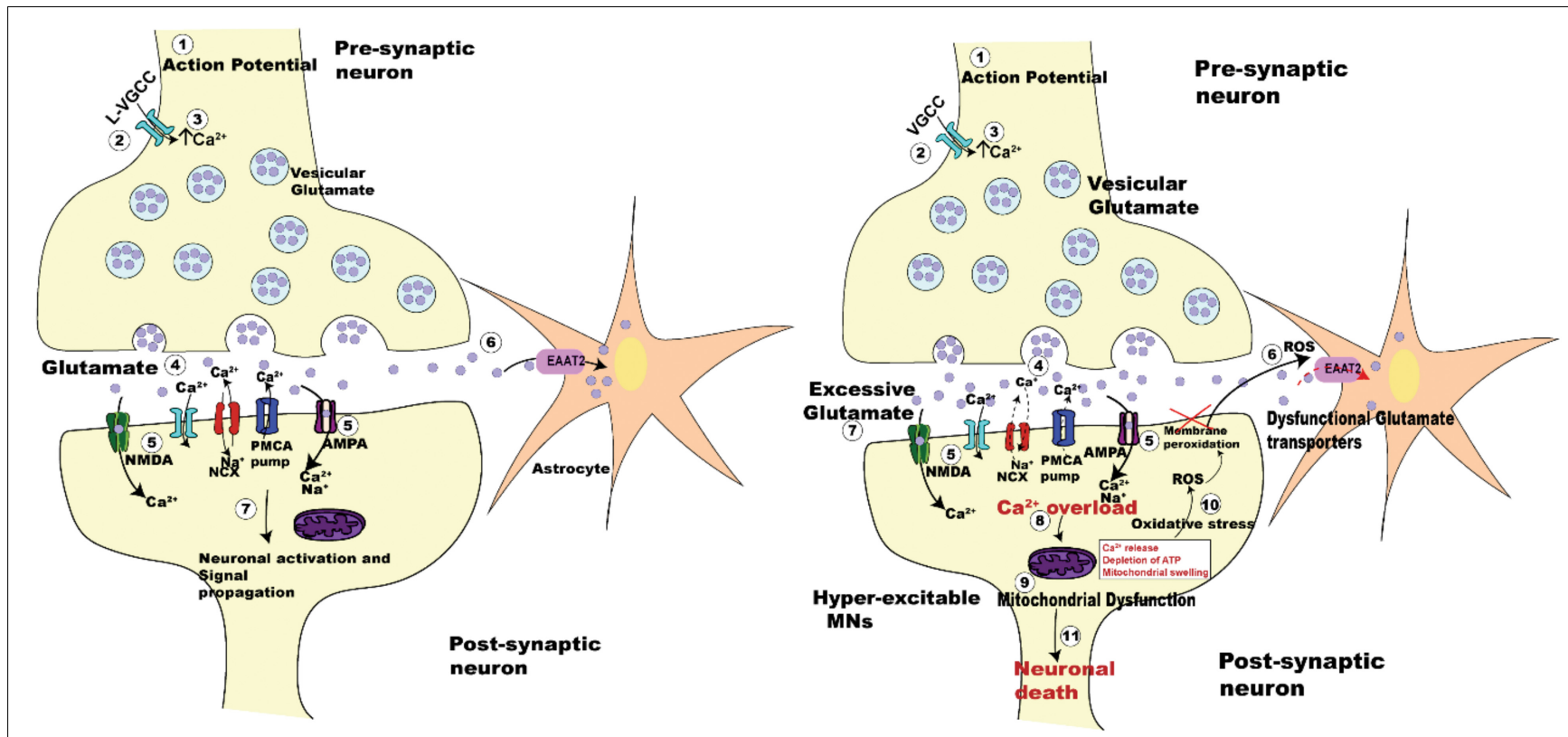

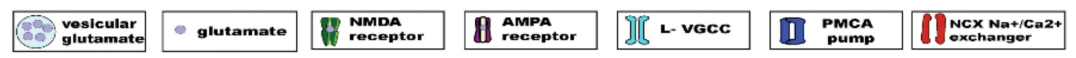

FIGURE 1 | Schematic diagrams showing the regulation of glutamatergic synaptic transmission at upper and lower MN synapses in normal and SOD1 ${ }^{\text {G93A }}$ mice. The arrival of the action potential (step 1), triggers the influx of $\mathrm{Ca}^{2+}$ ions into pre-synaptic terminal (step 2), the rise in intracellular calcium (step 3) in turn triggers the fusion of synaptic vesicles with the pre-synaptic membrane to release glutamate (light purple dots) from the terminal (step 4). Binding of glutamate to its postsynaptic receptors (NMDA, green; and AMPA, magenta; step 5), leads to the influx of $\mathrm{Ca}^{2+}$ ions. During this process, concentration of glutamate within the synaptic cleft is reduced by the uptake of glutamate into Astrocytes (orange star shaped cells) via EAAT2 glutamate transporters (pink; step 6). Within the post-synaptic neuron the influx of $\mathrm{Ca}^{2+}$ via glutamatergic receptors plus voltage gated $\mathrm{Ca}^{2+}$ channels, along with an influx of sodium ( $\mathrm{Na}^{+}$) ions lead to the activation of the postsynaptic neuron (step 7). The subsequent lowering of $\mathrm{Ca}^{2+}$ post-synaptic transmission is managed by extrusion of calcium via ATP pumps (PMCA pumps) and $\mathrm{Na}^{+} / \mathrm{Ca}^{2+}$ exchanger (NCX), plus calcium uptake into intracellular stores (ER and mitochondria) (Chio et al., 2012). The right panel shows the pathogenesis of glutamate induced excitotoxicity in ALS. Excessive glutamate released in the synaptic cleft triggers increased activation of the post-synaptic glutamate receptors (NMDA and AMPA receptors). This effect is enhanced due to dysfunctional glutamate transporters (EAAT2; step 6, right panel, red dashed arrow), which lengthen the persistence of glutamate within the synaptic cleft (step 7, right pane/), which further activates glutamatergic receptors. Impaired $\mathrm{Na}^{+} / \mathrm{Ca}^{2+}$ exchanger and ATP pumps in SOD1 G93A mice results in enhanced $\mathrm{Ca}^{2+}$ intracellularly (DeJesus-Hernandez et al., 2011; Sirabella et al., 2018). Generation of reactive oxygen species (ROS) causes neuronal membrane peri-oxidation impairing the glutamate transporters (EAAT2). The enhanced activation of these receptors leads to increased $\mathrm{Ca}^{2+}$ overload (step 8, right panel) in the post-synaptic neuron, which in turn leads to mitochondrial dysfunction (step 9, right panel), oxidative stress (step 10, right panel), and generation of reactive oxygen species (ROS) ultimately leading to motor neuron death (step 11, right panel).

the ATG start codon by alternate splicing to produce $17 \mathrm{BDNF}$ mRNA transcripts and 9 BDNF $5^{\prime}$ promoters (Aid et al., 2007; Pruunsild et al., 2007). The transcription of BDNF is neuronal activity-dependent and regulated by membrane depolarization. An increase in intracellular calcium $\left(\mathrm{Ca}^{2+}\right)$ concentration via activation of NMDA glutamate receptors or L-type voltage gated calcium channels (L-VGCC) following a depolarizing stimulus initiates transcription of the BDNF gene, predominantly at exon IV (Tao et al., 1998; Zheng et al., 2011). The promoter of BDNF exon IV contains $\mathrm{Ca}^{2+}$ response elements (CaRE) CaRE1 and CaRE3, which regulate transcription (Tao et al., 1998; Hong et al., 2008; Zheng et al., 2011). Cyclic AMP responsive element binding protein (CREB), a transcription factor, binds to these CaREs, which are phosphorylated by calcium/calmodulin (CaM)-dependent protein kinases, cAMP-dependent protein kinases and MAPK, activating the promoter and resulting in $\mathrm{Ca}^{2+}$ dependent transcription of BDNF mRNA at exon IV (Zheng et al., 2011).
Alternate splicing terminates transcription at two alternate polyadenylation points which shift the translation sites, giving rise to two distinct BDNF mRNA populations into specific neuronal compartments, allowing spatial and temporal translocation (Pruunsild et al., 2007; Notaras and van den Buuse, 2018). The short UTR BDNF transcripts are localized in the soma and maintain basal activity-dependent BDNF production. The long UTR BDNF transcript is targeted to the dendrites and displays robust translation on neuronal activation (An et al., 2008; Lau et al., 2010). BDNF localization is mostly somatodendritic (59\%) within dense core vesicles (Tongiorgi, 2008; Dieni et al., 2012) with only $29 \%$ targeted to the dendrites (Adachi et al., 2005). The specific compartmental translation of BDNF mRNA at long or short $3^{\prime}$ UTR is also aided by binding to numerous microRNAs such as miR30 , resulting in degradation of BDNF transcripts (Bartel, 2004; Mellios et al., 2008) and negative regulation of BDNF synaptogenesis (Shi, 2015). 
Translation of these distinct alternate BDNF mRNA transcripts gives rise to the precursor pre-pro $\mathrm{BDNF}$ in the endoplasmic reticulum (Foltran and Diaz, 2016; Kowianski et al., 2018), consisting of a signal peptide after the initiation codon and $\mathrm{N}$-glycosylation site on the pro region. It is then translocated to the Golgi apparatus, where the signal peptide pre-sequence is cleaved off to form pro-BDNF (30 kDa) (Lessmann et al., 2003). The pro-BDNF is then further processed either intracellularly or extracellularly, via the Golgi apparatus, into the trans-Golgi network (TGN) where the pro domain is proteolytically cleaved off to form pro-domain and mature BDNF and is secreted into the extracellular space (hence forth termed "BDNF") (Foltran and Diaz, 2016; Kowianski et al., 2018; Figure 2). The pro domain has been identified as an independent ligand itself and encodes the single nucleotide polymorphism of methionine to valine substitution at position 66 in the BDNF gene (Egan et al., 2003; Dieni et al., 2012; Notaras and van den Buuse, 2018). Intracellular cleavage of pro-BDNF in the TGN occurs via furin, while its cleavage to form BDNF in secretory vesicles requires convertases. The final molecular weight of BDNF is $14 \mathrm{kDa}$, consisting of 119 amino acids (Lu et al., 2005). The pro-BDNF is also secreted extracellularly, and then cleaved by proteases such as plasmin and metalloproteinases (MMP2 and MMP9) to form BDNF (Hwang et al., 2005; Mizoguchi et al., 2011). The extracellularly secreted pro-domain, pro-BDNF and BDNF are all biologically active and perform their various physiological functions (Figure 2).

The packaging and secretion of pro domain, pro-BDNF and BDNF from within the TGN into dense core secretory vesicles occurs via the constitutive secretory pathway and a preferential tightly controlled regulated pathway (Goodman et al., 1996; Lu, 2003; Brigadski et al., 2005). BDNF is secreted both pre- and post-synaptically, and undergoes anterograde and retrograde transport via autocrine and paracrine mechanisms (Cunha et al., 2010). These mechanisms modulate synaptic transmission and synaptogenesis (Cunha et al., 2010) via $\mathrm{Ca}^{2+}$ dependent mechanisms. BDNF is secreted pre-synaptically via increased intracellular influx of $\mathrm{Ca}^{2+}$ (Balkowiec and Katz, 2002). Post-synaptically, the secretion of BDNF is by regulated activity-dependent increases in $\mathrm{Ca}^{2+}$, entering via ionotrophic glutamate receptors and voltage-gated $\mathrm{Ca}^{2+}$ channels (Hartmann et al., 2001), or $\mathrm{Ca}^{2+}$ release from intracellular stores (Griesbeck et al., 1999) and release occurs via endosome like vesicles where exogenous BDNF is recycled (Sasi et al., 2017). Altogether, the above described synthesis, processing and secretion of BDNF gives rise to three functionally active proteins: the pro domain of BDNF, pro-BDNF and BDNF (mature BDNF) (Figure 2; Hempstead, 2015). Once released, they interact with their respective receptors to exert their distinct physiological functions.

\section{BDNF ISOFORMS AND THEIR RECEPTORS}

The three products of the BDNF gene bind to specific receptors and regulate distinct biological functions. The pro-domain of BDNF binds to sortilin, a member of vacuolar protein sorting 10 protein (vps10p) of the sorting receptor family (Teng et al., 2005; Anastasia et al., 2013) to trigger specific functions in developing and adult neurons. The pro-domain acts by inducing growth cone retraction (Anastasia et al., 2013), facilitating long term synaptic depression (LTD) in developing neurons (Mizui et al., 2016), and modulating synaptic spine density and neuronal network plasticity via a cytochrome $c$ caspase-3 mechanism in adult neurons (Guo et al., 2016). The pro-BDNF, comprising of the pro-domain and mature domain, act via preferential interactive binding to $\mathrm{p} 75$, a member of the tumor necrosis factor receptor family, and sortilin receptors, respectively (Teng et al., 2005; Kowianski et al., 2018) and with lower affinity binding to TrkB. The binding of pro-BDNF/p75/sortilin initiates the activation of c-Jun amino terminal kinase (JNK), Ras homolog gene family member A (RhoA), and nuclear factor kappa B (NF-кB) cascade (Reichardt, 2006; Anastasia et al., 2013; Kowianski et al., 2018). These signaling cascades (JNk, Ras, and NF- $\kappa \mathrm{B}$ ) in turn trigger a number of diverse cellular and morphological outcomes, such as neuronal apoptosis (Teng et al., 2005), neuronal growth cone development, and neuronal survival (Reichardt, 2006).

The third product, BDNF, binds with high affinity to TrkB of the Trk family of tyrosine kinases and with lower affinity to the p75 receptor (Chao and Hempstead, 1995; Reichardt, 2006). Activation of these two receptors is responsible for BDNF's known functions. In brief, BDNF/TrkB activation aids in neurogenesis, gliogenesis, neurite outgrowth, and enhanced neuronal survival (Huang and Reichardt, 2001; Vilar and Mira, 2016). In developing neuronal circuits, BDNF acts to regulate dendritic arborization and spine formation (Deinhardt and Chao, 2014; Gonzalez et al., 2016), and enhances long term synaptic potentiation (LTP) (Park and Poo, 2013; Leal et al., 2015). In mature neurons, BDNF is also required to sustain viability (Alcantara et al., 1997). BDNF mediates opposing actions on binding to the p75 receptor; while BDNF/TrkB enhances neuronal excitability and synaptic strength, BDNF/p75 acts to decrease excitability and synaptic strength and induce neuronal plasticity (Sasi et al., 2017), initiating JNK (Reichardt, 2006; Anastasia et al., 2013; Kowianski et al., 2018), triggering neuronal apoptosis (Teng et al., 2005), and NF-кB cascade regulating of neuronal growth cone development and navigation and neuronal survival. The $\operatorname{TrkB}$ and $\mathrm{p} 75$ receptor have somadendritic distribution (Bronfman and Fainzilber, 2004), where TrkB is localized to the pre- and post-synaptic membranes and intracellularly (Gomes et al., 2006; Song et al., 2017).

Brain derived neurotrophic factor undergoes slow exocytosis (Brigadski et al., 2005) following depolarization and stimulation of glutamate receptors (Righi et al., 2000; Kohara et al., 2001). Thus, activity-dependent BDNF secretion can be induced by numerous stimuli including high potassium, glutamate and the neurotrophin itself, dependent on intracellular $\mathrm{Ca}^{2+}$ increase (Blochl and Thoenen, 1995; Goodman et al., 1996; Canossa et al., 1997).

\section{The TrkB Receptor}

The $\operatorname{TrkB}$ receptor is encoded by a single $\operatorname{TrkB}$ gene, the NTRK2 gene encoding 24 exons located on chromosome 9q22 (Schneider and Schweiger, 1991; Nakagawara et al., 1995). TrkB 


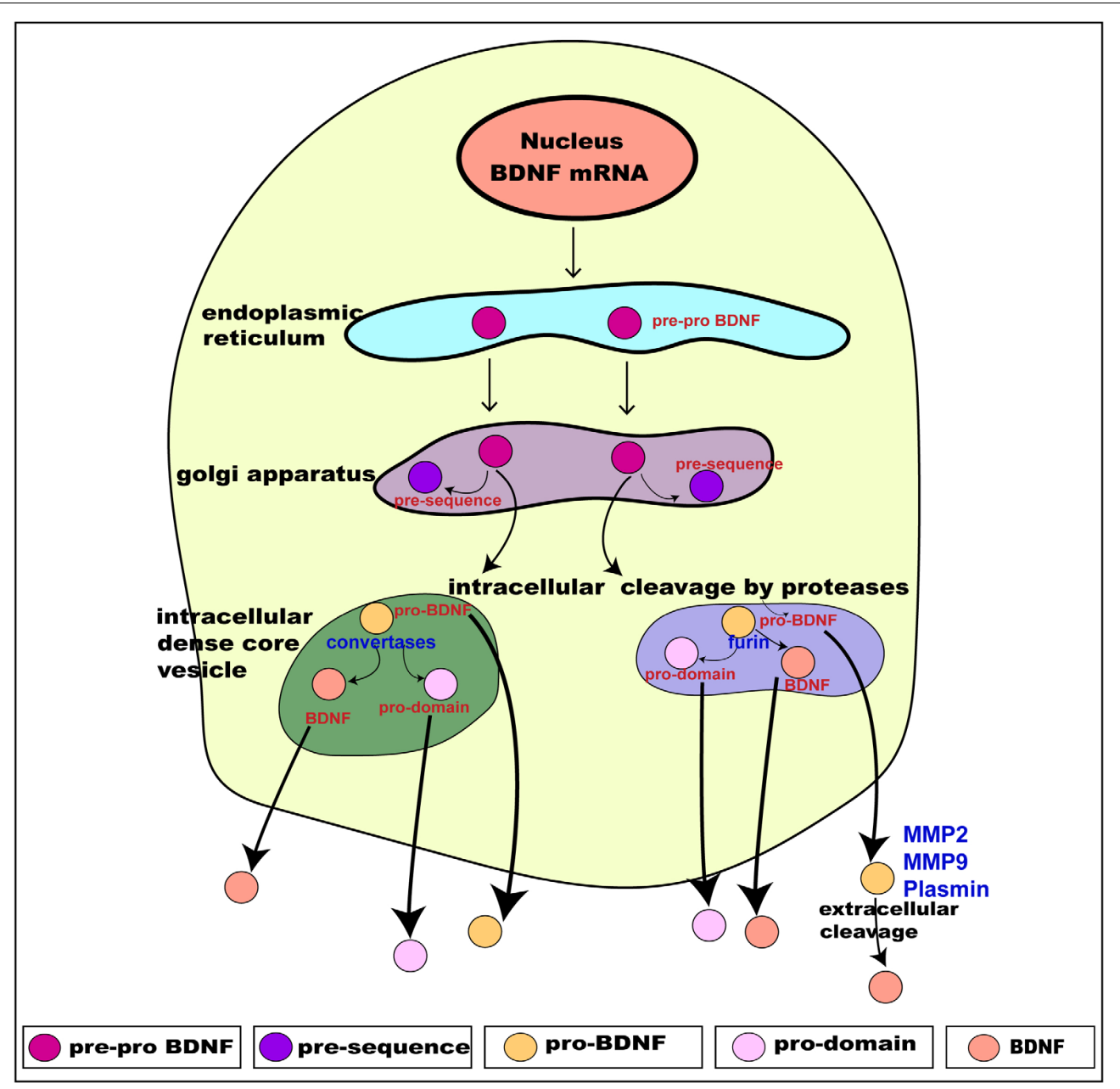

FIGURE 2 | Schematic presentation of BDNF synthesis from translation, intracellular processing through to its secretion. BDNF is synthesized from the BDNF gene in a multi-step process. Intracellularly, the pre-pro BDNF is produced in the endoplasmic reticulum which is then translocated toward the Golgi apparatus, where the pre-sequence is cleaved off to form pro- BDNF. The pro-BDNF is further processed, via the Golgi apparatus, into the trans-Golgi network (TGN) where the pro domain is cleaved off by proteases to form mature BDNF (BDNF). The pro-BDNF is proteolytically cleaved by furin or convertase and is intracellularly secreted as BDNF. Both pro-BDNF and BDNF are preferentially grouped and packaged into secretory dense core-vesicles and secreted extracellularly via exocytosis. The extracellularly secreted pro-BDNF is then processed and catalyzed by proteases such as plasmin and metalloproteinases (MMP2 and MMP9) to form BDNF. As a result, three functionally active isoforms, namely pro-domain, pro-BDNF and BDNF are secreted extracellularly. Adapted from Kowianski et al. (2018).

consists of three domains: - an extracellular ligand binding domain, a transmembrane domain and an intracellular tyrosine kinase domain. One full- length $\operatorname{TrkB}(\operatorname{TrkB})$ contains an extracellular transmembrane domain, consisting of a cysteine rich cluster followed by 3 leucine repeats, a cysteine cluster followed by 2 immunoglobulin (Ig1 and Ig2) domains; and an intracellular cytoplasmic tyrosine kinase domain acting as a phosphorylation dependent docking site (Schneider and Schweiger, 1991; Tejeda and Diaz-Guerra, 2017). The Ig domain in exon 12 directs binding specificity to its ligand, BDNF. Exon 15 encodes the transmembrane domain, and exon 20-24 the intracellular tyrosine kinase domain (Middlemas et al., 1991). The first five exons serve as the transcription initiation sites and display alternate splicing patterns (Stoilov et al., 2002). Exon five also serves as a ribosomal entry site, directing the start of translation and producing four isoforms of TrkB receptors in humans (Luberg et al., 2010; Sasi et al., 2017). Other splice variants are two truncated TrkB (TrkB-T1) isoforms, TrkB-T2, TrkB- Shc lacking tyrosine kinase domain, and a TrkB-TK with a non-viable catalytic domain. Truncated TrkB receptors (TrkB-T1 and TrkB-T2) are the product of alternate splicing at exon 18. These TrkB isoforms are activated on binding to BDNF to initiate downstream signaling.

\section{BDNF/TrkB}

Brain derived neurotrophic factor binds to the TrkB receptor, both TrkB-T and TrkB (full length) with similar affinity (Sasi et al., 2017). Exactly how TrkB receptor isoforms coordinate and produce a precise cellular and biological function is not yet clearly understood. BDNF binding to the TrkB-T isoform has been identified as a dominant negative 
pathway (Fenner, 2012; Notaras and van den Buuse, 2018). More recently, the TrkB-T receptor has also been reported to have functions apart from dominant negative regulation, including the following: metabolite release (Baxter et al., 1997; Fenner, 2012); BDNF sequestration and translocation (Fryer et al., 1996); filopodia and neurite outgrowth (Fryer et al., 1997; Yacoubian and Lo, 2000; Fenner, 2012); and astrocytic cytoskeletal remodeling via Rho GTPase (Ohira et al., 2006; Fenner, 2012). Additionally, alterations in expression of TrkB-T has also been shown to alter neuronal viability, resulting in neurodegeneration (Vidaurre et al., 2012), indicating a biological function of $\operatorname{TrkB}-\mathrm{T}$. However, the mechanism driving the function of TrkB-T is not well understood. Given that this review focusses on the interaction of BDNF with the $\operatorname{TrkB}$ receptor, the following sections will only address
BDNF-TrkB interactions together, independent of BDNF's nonTrkB functions.

Binding of BDNF to TrkB initiates two different categories of cascades: a fast acting BDNF/TrkB cascade that excites neurons or a slow acting occurring over minutes to hours. The action of BDNF markedly differs between these two categories (Kafitz et al., 1999; Ji et al., 2010). Additionally, evidence suggests that the well-studied effect of BDNF/TrkB on cell survival and plasticity are mediated by TrkB-FL (Klein et al., 1993; Carim-Todd et al., 2009). Once BDNF binds to TrkB, ligand-mediated dimerization of the complex occurs at the cell surface, followed by autophosphorylation of specific tyrosine residues in the cytoplasmic domain, leading to activation of three interconnected intrinsic intracellular cascades (Chao, 2003; Cunha et al., 2010; Figure 3).

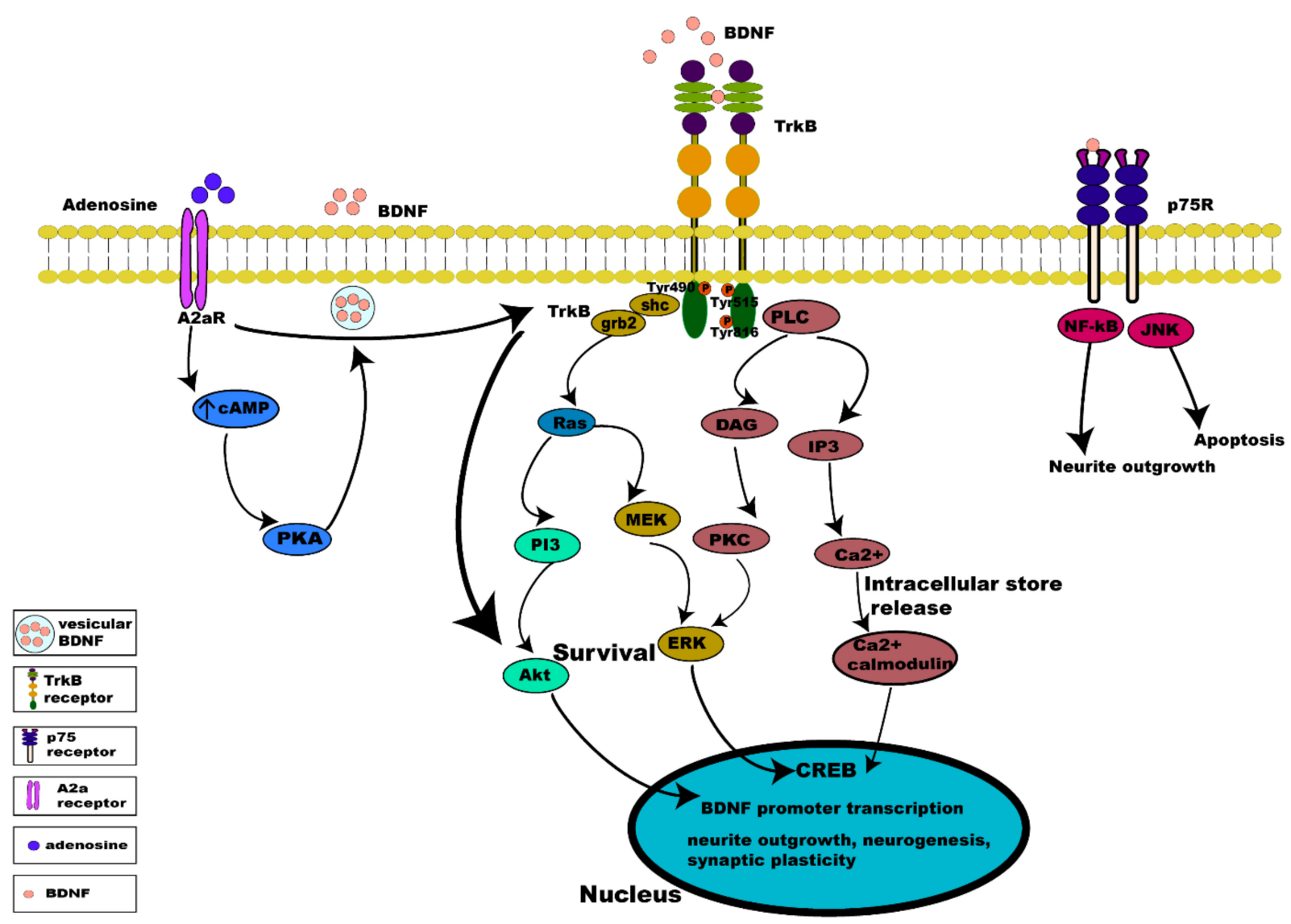

FIGURE 3 | Intrinsic intracellular signaling cascades of BDNF-TrkB and TrkB-A ${ }_{2 a}$ receptors. BDNF-TrkB activation predominantly initiates MAPK, PI3K, and PLC $\gamma$ signaling pathways. Activation of the TrkB receptor at its Tyr490 and Tyr515 residue recruits Shc adaptor protein leading to binding of growth factor receptor bound protein 2 (grb2) which binds with GTPase Ras to form a complex and initiate extracellular signal regulated kinase (ERK) activation which in turn activates the mitogen activated protein kinase MAPK/ERK pathway, which results in the activation of CREB transcription factor. Activation of Tyr515 residue also activates the PI3K signaling pathway, incorporating combined actions of Ras and activating the PI3/Akt and MEK/MAPK pathways. Both MAPK and PI3K signaling exert neurotrophic functions of survival, growth and differentiation, via activation transcription factors (CREB and C-myc). Phosphorylation of the TrkB receptor at its Tyr816 residue activates the phospholipase $\mathrm{C} \gamma$ (PLC $\gamma$ ) pathway, generating inositol-1, 4, 5-triphosphate (IP3) and diacylglycerol (DAG). The PLC $\gamma /$ IP3 pathway results in calcium release from intracellular stores, in turn activating $\mathrm{Ca}^{2+} /$ CaMKII. DAG activates PKC, leading to synaptic plasticity. pro-BDNF/p75 initiates JNK signaling (Reichardt, 2006; Anastasia et al., 2013; Kowianski et al., 2018) triggering neuronal apoptosis (Teng et al., 2005), and the NF-kB signaling cascade regulation of neuronal growth cone development and navigation, and neuronal survival. Like BDNF, neuronal activity promotes release of adenosine which binds to $A_{2 a} R s$ to activate adenylyl cyclase leading to production of CAMP further activating PKA downstream which controls $\mathrm{Ca}^{2+}$ dependent BDNF release. Activation of $\mathrm{A}_{2 a} \mathrm{Rs}$ also transactivates TrkB, initiating the TrkB-Akt pathway promoting neuronal survival. 


\section{THE MAPK PATHWAY}

Activation of the TrkB receptor at its Tyr490 and Tyr515 residue causes the docking of Shc adaptor protein (Src- homology 2domain) at these tyrosine sites and recruits growth factor receptor bound protein 2 (grb2) which binds with GTPase Ras to form a complex, and initiates extracellular signal regulated kinase (ERK) activation (Wheaton et al., 2007). ERK activation in turn activates the mitogen activated protein kinase MAPK/ERK pathway. MAPK/ERK kinases are able to phosphorylate and activate the transcription factor cAMP response element binding protein (CREB) (Huang and Reichardt, 2003; Begni et al., 2017). The phosphorylated CREB is then translocated into the nucleus, where it induces BDNF transcription by binding to BDNF promoters (Shaywitz and Greenberg, 1999). Binding to BDNF promoters drives BDNF expression to regulate neuronal survival, differentiation and synaptic plasticity (Patapoutian and Reichardt, 2001). In addition, this activation of BDNF expression induces activation of AMPA receptors on stimulation by BDNF (Song et al., 2013).

\section{THE PI3K PATHWAY}

Activation of the PI3K pathway incorporates combined actions of Ras at the Tyr515 residue, which activates multiple cascades, namely the PI3/Akt and MEK/MAPK pathways. Activation of the $\mathrm{PI} 3 \mathrm{~K} / \mathrm{Akt}$ cascade regulates proteins such as $\mathrm{BAD}(\mathrm{Bcl}-2$ antagonist of cell death) and GSK-3 $\beta$ (glycogen synthase kinase $3 \beta$ ), essential for neuronal survival, growth and differentiation, and is activated by $\mathrm{Ca}^{2+}$ influx via L-type voltage gated calcium channels (L-VGCC) (Brunet et al., 2001). Activation of mammalian target of rapamycin (mTOR) by BDNF also enhances local BDNF translation to dendrites at active synapses via the PI3K pathway (Schratt et al., 2004).

\section{THE PLC $\gamma$ PATHWAY}

The phosphorylation of the TrkB receptor at its Tyr816 residue activates the phospholipase $\mathrm{C} \gamma$ (PLC $\gamma$ ) pathway, generating inositol-1,4,5-triphosphate $\left(\mathrm{IP}_{3}\right)$, and diacylglycerol (DAG) which is important for survival, neurite outgrowth and synaptic plasticity. BDNF via the $\mathrm{PLC} \gamma / \mathrm{IP}_{3}$ pathway results in calcium release from intracellular stores activating CaMKII $\left(\mathrm{Ca}^{2+} /\right.$ calmodulin dependent protein kinase) which in turn activates CREB phosphorylation (Minichiello et al., 2002; Tejeda and Diaz-Guerra, 2017). The generation of DAG on the other hand, activates PKC (Bellingham, 2013a) which is translocated to the membrane for further activation and phosphorylation of ERK leading to synaptic plasticity (Minichiello et al., 2002; Chao, 2003).

The BDNF-TrkB complex not only activates on its transmembrane surface (described above) but it also internalizes via endosomes (both early and late endosomes) to activate downstream pathways. This BDNF-TrkB signaling via endosome also determines the cellular fate of BDNF-TrkB complexes, which can be transported retrogradely, recycled back to the membrane, or prepared for degradation by lysosomes (Yamashita and Kuruvilla, 2016).

\section{BDNF: ROLE IN SYNAPTIC TRANSMISSION}

Synaptic transmission is a highly complex trans-neuronal process, occurring at the synapse between a pre-synaptic (axonal) terminal and a post-synaptic (typically dendritic) membrane. BDNF elicits rapid effects on synaptic transmission and membrane excitability, via activation of pathways in both the pre- and post-synaptic compartments. In the presynaptic compartment, BDNF causes release of glutamate and GABA, via the TrkB-ERK mediated pathway (Jovanovic et al., 2000). Enhanced glutamate release at glutamatergic synapses is mediated by an increase in docked vesicles at presynaptic active zones (Tyler and Pozzo-Miller, 2001). For example, BDNF application to hippocampal and cortical neuron cultures (Levine et al., 1995; Lessmann, 1998) and slice preparations (Kang and Schuman, 1995; Kang et al., 1997) potentiates excitatory neurotransmission, increasing glutamate release. Consequently, BDNF application onto brain slices induces hyper-excitability (Scharfman, 1997), which is consistent with observations in transgenic mice over-expressing BDNF (Croll et al., 1999). In the post-synaptic compartment, BDNF can also enhance synaptic responses by increasing the open probability of NMDA glutamate receptors (Rose et al., 2004). Hence, in the context of ALS, the increased neuronal activity observed in $\mathrm{hSOD} 1^{G 93 A}$ mice is capable of increasing BDNF secretion, which in turn can increase release of glutamate to trigger excitotoxicity, leading to $\mathrm{MN}$ degeneration. Indeed, BDNF has been shown to enhance $\mathrm{MN}$ death by glutamate excitotoxicity, via activation of $\operatorname{TrkB}(\mathrm{Hu}$ and Kalb, 2003; Mojsilovic-Petrovic et al., 2006). Together, these observations highlight a possible role for BDNF in the death of MNs in ALS.

\section{MECHANISMS OF BDNF-MODIFIED NEUROTRANSMISSION}

Brain derived neurotrophic factor also modifies neurotransmission by altering the expression of pre-synaptic proteins that regulate neurotransmitter release (Andreae and Burrone, 2018). For example, in BDNF deficient mice, decreased synaptic transmission correlates with a drop in the number of docked synaptic vesicles (Carter et al., 2002). This is also correlated with decreases in synapsin, synaptophysin and synaptobrevin - presynaptic proteins required for vesicle docking and exocytosis at release sites (i.e., active zones) (Martinez et al., 1998; Pozzo-Miller et al., 1999; Jovanovic et al., 2000). These physiological and molecular changes are also present in TrkB knockout mice (Martinez et al., 1998). Thus, BDNF can stimulate synaptic transmission via three mechanisms: (1) increasing the number of synaptic vesicles at the active zone, (2) increasing the 
postsynaptic receptor response, and (3) increasing the overall number of synapses per neuron (Bradley and Sporns, 1999).

\section{TrkB RECEPTOR CAN BE ACTIVATED INDEPENDENT OF BDNF}

Tropomysin related kinase $\mathrm{B}$ receptor is capable of autophosphorylation and activation of downward cascades independent of its ligand, BDNF. Activation of TrkB receptors in the absence of BDNF occurs via a mechanism known as trans-activation, which involves specific $G$ protein coupled receptors (GPCR), such as the $\mathrm{A}_{2 a}$ adenosine receptor $\left(\mathrm{A}_{2 a} \mathrm{R}\right)$ present both pre- and post-synaptically (Chao, 2003; Sebastiao et al., 2018). Adenosine is a key neuromodulator produced both extracellularly and intracellularly in neurons and glial cells (Moreau and Huber, 1999). Extracellularly, it is produced by ectonucleotidase degradation of ATP released by neurons and astrocytes, and intracellularly by production during breakdown of ATP during high energy demand, followed by transport into the extracellular space (Jacobson and Gao, 2006). Adenosine directly regulates synaptic transmission and plasticity, as well as modulating neurotransmission and neurotrophins (Sebastiao and Ribeiro, 2009). Pre-synaptically the activation of $\mathrm{A}_{2 a} \mathrm{Rs}$ increases the release of glutamate (Ciruela et al., 2010; Cunha, 2016) and the activation of NMDA receptors (Azdad et al., 2009; Higley and Sabatini, 2010; Sarantis et al., 2015), thus facilitating LTP. Transactivation of TrkB by $\mathrm{A}_{2 a}$ Rs is mediated by the Src family of protein, such as Fyn (Lee and Chao, 2001), in a slow acting cascade occurring over minutes to hours. TrkB/ $\mathrm{A}_{2 a} \mathrm{R}$ interaction allows transactivation of a downstream protective TrkB-Akt pathway (Mojsilovic-Petrovic et al., 2006). Postsynaptic activation of $\mathrm{A}_{2 a} \mathrm{Rs}$ also triggers calcium dependent processes, through L-type voltage gated calcium channels and NMDA receptors, activating adenylyl cyclase and leading to increased cAMP and PKA phosphorylation, which in turn influences $\mathrm{Ca}^{2+}$ dependent transcription of BDNF mRNA (Zheng et al., 2011) and BDNF secretion (Tebano et al., 2010) (summarized in Figure 3).

A study by Diogenes et al. (2004), demonstrated that BDNF alone without prior depolarization was devoid of effects on neurotransmission, while enhancement of synaptic transmission by BDNF in the hippocampus was facilitated by pre-synaptic activity-dependent adenosine release via $\mathrm{A}_{2 A}$ Rs. This excitatory action of BDNF can be blocked by a TrkB inhibitor, an $\mathrm{A}_{2 A} \mathrm{R}$ antagonist or by a PKA inhibitor, thus indicating that activation of $\mathrm{A}_{2 A}$ Rs facilitates BDNF modulation of synaptic transmission (Diogenes et al., 2004). Additionally, the role of $A_{2 a}$ Rs in regulating $\mathrm{BDNF}$ function was further supported in a study using $\mathrm{A}_{2 a} \mathrm{R}$ KO mice, which showed no increase in field EPSCs after BDNF application, whereas in normal hippocampus slices BDNF induced enhanced field EPSCs and EPSCs, and this effect was blocked by $\mathrm{A}_{2 a} \mathrm{R}$ blockers, clearly indicating that activation of $\mathrm{A}_{2 a} \mathrm{Rs}$ is required for normal BDNF levels and BDNF's potentiation of synaptic transmission (Tebano et al., 2008). Taking into account the enhanced glutamate present in MNs in ALS, the $\mathrm{A}_{2 a} \mathrm{Rs}$ is considered as a potential neuroprotective therapeutic agent to ameliorate glutamate induced excitotoxicity in ALS, reinforcing the significance of TrkB transactivation.

In addition to TrkB transactivation by $\mathrm{A}_{2 a}$ Rs, GPCR mediated TrkB transactivation also occurs via other mechanisms. For example, in embryonic cortical neurons TrkB is transactivated by activation of epidermal growth factor (EGF) leading to migration of early cortical neurons to form a differentiated cortical layer (Puehringer et al., 2013). Similarly in striatal neurons, activation of dopamine 1 (D1) receptors leads to transactivation of $\operatorname{TrkB}$ functioning in axonal growth and growth cone during neuronal development (Iwakura et al., 2008). Furthermore, in hippocampal mossy fiber neurons TrkB is transactivated by zinc, which is secreted along with glutamate in response to neuronal activity leading to potentiation of mossy fiber synapses, thus regulating synaptic plasticity (Huang et al., 2008). Hence, considering the role of $\mathrm{BDNF} / \mathrm{TrkB}$ during development and pathological situations such as in neurodegenerative diseases, TrkB transactivation offers alternative methods to modulate $\mathrm{BDNF} /$ TrkB, opening new therapeutic avenues for the treatment of neurodegenerative disorders.

\section{BDNF/TrkB INTERACTS WITH $\mathrm{Ca}^{2+}$ AND GLUTAMATE}

The interplay between BDNF and glutamate has been well established in many previous studies. Glutamate is a major excitatory neurotransmitter in the central nervous system (CNS) known for its activity-dependent interplay with neurotrophic factors during development and in mature neurons. Postsynaptically, the effect of glutamate is mediated by activation of two major ionotrophic glutamate receptors; AMPA receptors and NMDA receptors (Rao and Finkbeiner, 2007; Mattson, 2008). Pre-synaptic depolarization results in glutamate release, activation of AMPA and NMDA receptors post-synaptically, and secretion of BDNF in the extracellular space (Nagappan and $\mathrm{Lu}, 2005)$. BDNF-induced pre-synaptic glutamate release is mediated via TrkB-ERK signaling (Jovanovic et al., 2000), and post-synaptic modulation of glutamate receptors occurs by phosphorylation of the NMDA receptor subunit NR2B (Cunha et al., 2010). Furthermore, BDNF also enhances AMPA receptor surface expression, thus increasing post-synaptic responses to glutamate (Narisawa-Saito et al., 2002; Cunha et al., 2010) - an effect mediated via ERK (Li and Keifer, 2009). BDNF treatment also leads to phosphorylation of NMDAR subunit NR1 (Slack and Thompson, 2002), altering NMDAR localization at synapses (Gomes et al., 2006).

In addition to these pre- and postsynaptic effects on glutamatergic transmission, TrkB activation also modulates ion channels that can alter neuronal excitability, including $\mathrm{Na}^{+}$, $\mathrm{Ca}^{2+}$, and $\mathrm{K}^{+}$channels through intracellular cascades (Blum et al., 2002; Tucker and Fadool, 2002). For example, BDNF/TrkB activation alters neuronal excitability by gating of $\mathrm{Na}^{+}$current via Nav1.9 (Blum et al., 2002). Metabotropic receptors such as $\mathrm{A}_{2 a}$ Rs also activate TrkB to induce release of intracellular $\mathrm{Ca}^{2+}$ from ER stores. This in turn activates a PLC cascade to 
generate inositol triphosphate (IP3) which releases $\mathrm{Ca}^{2+}$ from IP3-sensitive stores, activating PKC.

Considering the interplay between the actions of BDNF and glutamate, there are several possible avenues leading to interactions between neuronal activity and BDNF. Synaptic hyper-excitability and increased intrinsic excitability of susceptible neurons in ALS are clearly observed in human patients (Bostock et al., 1998; Mogyoros et al., 1998; Kanai et al., 2006; Sirabella et al., 2018) and in animal models of ALS (van Zundert et al., 2008; Fogarty et al., 2015; Sirabella et al., 2018). The increased firing and synaptic activation of glutamate receptors would likely result in increased intracellular $\mathrm{Ca}^{2+}$, enhancing BDNF release, which could trigger further release of glutamate. This proposed mechanism would perturb the neuron's ability to regulate its activity, leading to glutamate excitotoxicity and neuronal death (Figure 4).

\section{BDNF/TrkB Crosstalk With Inhibitory Neurotransmission}

Considering that the physiological functioning of neurons requires a balance between excitatory and inhibitory neurotransmission, hyper-excitability of MNs in ALS can also result from reduced inhibition. $\gamma$-aminobutyric acid (GABA) and glycine are the primary neurotransmitters regulating chloride $\left(\mathrm{Cl}^{-}\right)$mediated inhibition in CNS by binding to their postsynaptic receptors. The strength of synaptic inhibition critically depends on intracellular $\mathrm{Cl}^{-}$concentration, hence on $\mathrm{Cl}^{-}$ homeostasis (Rivera et al., 1999). A key regulator of $\mathrm{Cl}^{-}$ concentration, the potassium chloride cotransporter (KCC2) (Rivera et al., 1999) has been shown to be depleted in MNs (Boulenguez et al., 2010; Fuchs et al., 2010), contributing to the hyper-excitability of MNs. Furthermore, BDNF/TrkB has been shown to be associated with KCC2 regulation (Lee-Hotta et al., 2019) and BDNF/TrkB dependent KCC2 depletion has also been described in MNs (Fuchs et al., 2010; Lee-Hotta et al., 2019). Thus, BDNF/TrkB activation down regulates the expression of KCC2 thereby reducing the $\mathrm{Cl}^{-}$extrusion capacity in MNs (Rivera et al., 2002, 2004), suppressing $\mathrm{Cl}^{-}$dependent inhibition which as a result makes the neuron hyper-excitable. Also, the role of microglia induced synaptic inhibition cannot be ignored because KCC2 modulation is required to achieve synaptic balance (Fiumelli and Woodin, 2007; Ferrini and De Koninck, 2013). Indeed, BDNF is released not only from neurons but also from microglia, making BDNF/TrkB a major signaling point of interaction between microglia and neuron (Trang et al., 2011), eventually affecting $\mathrm{Cl}^{-}$homeostasis (Rivera et al., 2002, 2004; Coull et al., 2005; Zhang et al., 2008). Besides, microglial activation and dysfunction observed in MNs of ALS mice contributes to the progression of disease (Brites and Vaz, 2014) making microglial $\mathrm{BDNF}$ a potential actor.

\section{DETRIMENTAL EFFECTS OF BDNF/TrkB IN ALS}

The ability of BDNF/TrkB to promote neuronal survival and resistance to toxic insults is well characterized
(Kowianski et al., 2018). Several studies documented the neuroprotective effects of BDNF on glutamate induced excitotoxicity in vivo (Bemelmans et al., 2006; Henriques et al., 2010) and functional recovery of motor neurons in vitro following exogenous BDNF application (Shruthi et al., 2017). Contrary to the view stated in this review, potentiating BDNF has been one of the strategies to delay the disease progression of ALS. The modulation of TrkB via small molecule drug formulations to enhance BDNF signaling also enhanced neuronal survival in degenerating neurons in vitro (Guerzoni et al., 2017) and improved motor function and motor neuron loss in ALS model mice (Korkmaz et al., 2014). BDNF potentiation has also been demonstrated to enhance $\mathrm{MN}$ survival in vitro (Tsai et al., 2013) and in other neurodegenerative diseases (Aytan et al., 2018). Additionally, transactivating $\operatorname{TrkB}$ by $\mathrm{A}_{2 a}$ receptors has also been reported to enhance survival of $\mathrm{MNs}$ in culture (Komaki et al., 2012). However, despite these neuroprotective effects observed there is also evidence to show that therapeutic interventions aimed at enhancing $\mathrm{BDNF} / \mathrm{TrkB}$ are unable to promote survival or prevent death of neurons in vivo (The BDNF Study Group Phase III, 1999; Silani et al., 2001; Pansarasa et al., 2018). This suggests that the detrimental actions of BDNF also need to be considered. Under certain circumstances, many studies report that BDNF/TrkB can exert negative effects on $\mathrm{MN}$ survival, making $\mathrm{MNs}$ more vulnerable to insults ( $\mathrm{Hu}$ and Kalb, 2003; Mojsilovic-Petrovic et al., 2006). Moreover, BDNF is potent at enhancing excitotoxic insult, by enhancing glutamatergic activity in neurons (Kafitz et al., 1999). Several studies report BDNF and $\operatorname{TrkB}$ to be key players in rendering MNs vulnerable to excitotoxic insult (Fryer et al., 2000; Hu and Kalb, 2003; Mojsilovic-Petrovic et al., 2005). Additionally, muscle from ALS patients expresses elevated levels of BDNF, suggesting the possible negative action of BDNF (Kust et al., 2002). Furthermore, BDNF can accelerate glutamate-induced death in rat neuroblastoma cells, and this effect was promoted by TrkB activation (Maki et al., 2015). BDNF also elicited glutamate excitotoxicity in cultured cortical neurons (Koh et al., 1995; Kim et al., 2003), and TrkB inhibition ameliorated these detrimental effects of BDNF (Kim et al., 2003). Additional evidence for the role of BDNF/TrkB in promoting neuronal death comes from a study, where exogenous nitic oxide $(\mathrm{NO})$ /sodium nitroprusside-induced cell death in cortical neurons was enhanced by BDNF, and this effect was inhibited by TrkB antagonism (Ishikawa et al., 2000). Fryer et al. (1999, 2000) also demonstrated that BDNF enhanced glutamate excitotoxicity in cultured embryonic spinal cord MNs, and this response involved activation of TrkB. Furthermore, directly blocking TrkB activation protected embryonic cultured MNs from toxic insults thought to be involved in the pathogenesis of ALS, such as excitotoxicity and the presence of SOD1 mutations (Hu and Kalb, 2003; Mojsilovic-Petrovic et al., 2006; Jeong et al., 2011). Additionally, TrkB-T receptors have been shown to be enhanced in MNs in ALS and deletion of TrkB-T receptors delayed the progression of disease in SOD ${ }^{G 93 A}$ mice (Yanpallewar et al., 2012) which further adds to the role of TrkB in ALS. Similarly, impaired BDNF/TrkB signaling and altered TrkB-T isoform was observed in the neuromuscular 


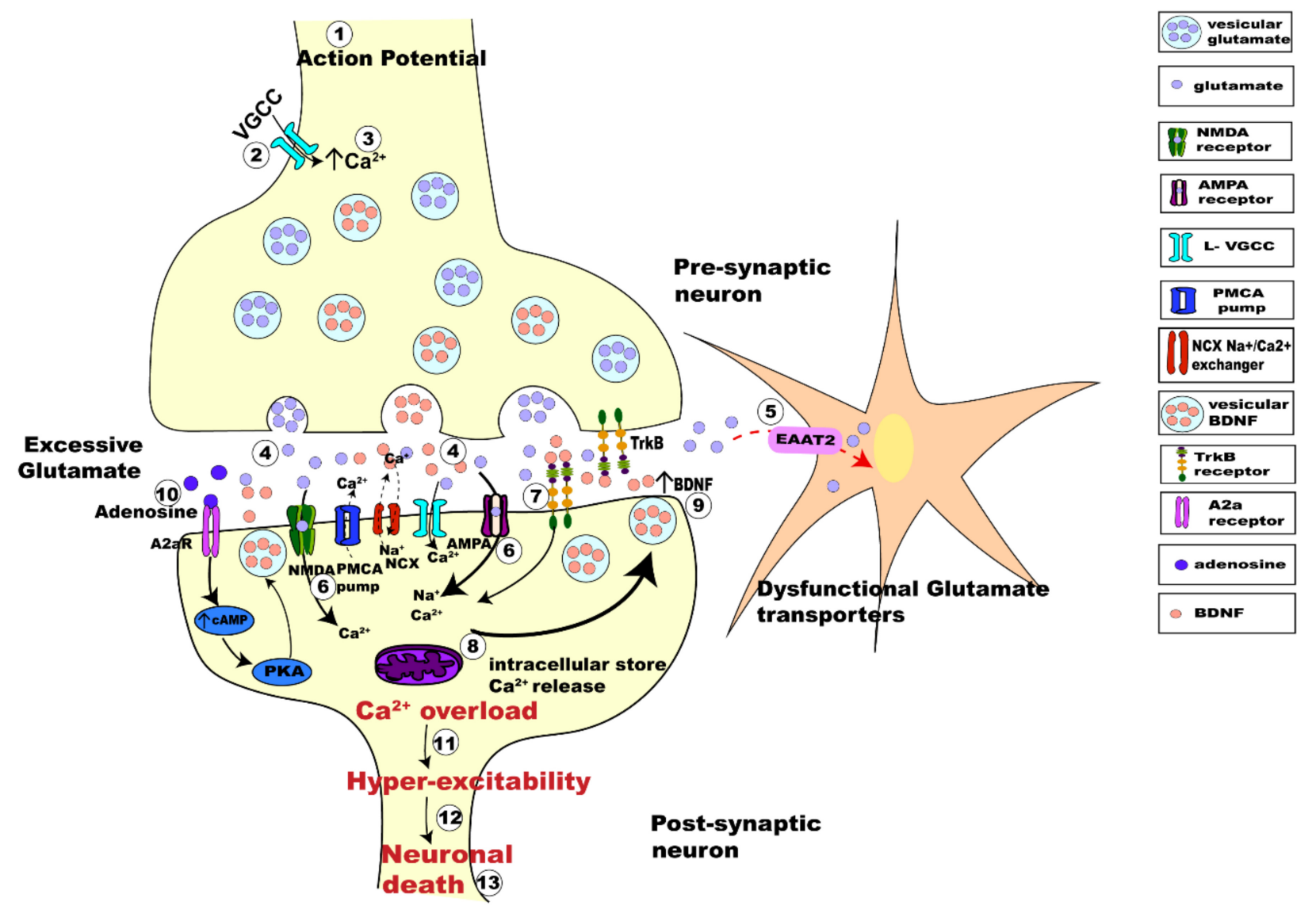

FIGURE 4 | Schematic figure representing activity-dependent interplay between glutamate-induced excitotoxicity and BDNF-TrkB signaling. The arrival of action potential (step 1), triggers the influx of $\mathrm{Ca}^{2+}$ ions into pre-synaptic terminal (step 2), the rise in intracellular calcium (step 3) in turn triggers the fusion of synaptic vesicles with pre-synaptic membrane to release glutamate (light purple dots) from the terminal (step 4). Membrane depolarization also results in BDNF secretion (orange dots) (step 4) and release pre-synaptically into the synaptic cleft. Dysfunctional glutamate transporters (EAAT2) in ALS results in retention of excessive glutamate in the synaptic cleft (step 5). Post-synaptically, $\mathrm{Ca}^{2+}$ enters through voltage gated calcium channels and via calcium-permeable glutamate receptors (NMDA, green; AMPA magenta; step 6). BDNF binding to TrkB alters the neuronal excitability of ion channels and also enhances post-synaptic glutamate receptor activation causing influx $\mathrm{Ca}^{2+}$ of ions post-synaptically (step 7). Excessive glutamate in the synaptic-cleft over-activates its receptors increasing the intracellular $\mathrm{Ca}^{2+}$ furthermore (step 8). Impaired $\mathrm{Na}^{+} / \mathrm{Ca}^{2+}$ exchanger and ATP pumps in SOD1 ${ }^{\mathrm{G} 93 A}$ mice results in enhanced $\mathrm{Ca}^{2+}$ intracellularly (DeJesus-Hernandez et al., 2011; Sirabella et al., 2018). $\mathrm{Ca}^{2+}$ released from the intracellular store adds to the $\mathrm{Ca}^{2+}$ concentration (step 8). Enhanced Ca ${ }^{2+}$ in the post-synaptic neuron also triggers increased $\mathrm{Ca}^{2+}$ dependent secretion and release of BDNF extracellularly causing enhanced BDNF extracellularly (step 9). Trans-activation of TrkB by $\mathrm{A}_{2 a}$ Rs also triggers calcium dependent signaling, activating adenylyl cyclase and leading to increased CAMP and PKA phosphorylation, which in turn influences BDNF secretion (step 10). This increased BDNF in the synaptic cleft binds to its receptors TrkB and repeats the process of $\mathrm{Ca}^{2+}$ influx and modulation of glutamate receptors, eventually leading to $\mathrm{Ca}^{2+}$ overload (step 11) making the neurons hyper-excitable (step 12) which eventually leads to neuronal death (step 13).

junction of pre-symptomatic SOD $1^{G 93 A}$ mice (Just-Borras et al., 2019). Furthermore, removal of the TrkB-T receptor at the pre-symptomatic stage in SOD $1^{G 93 A}$ mice improved the disease symptoms rescuing hippocampal interneurons and regulating long term potentiation (Quarta et al., 2018) found to be enhanced in ALS (Spalloni et al., 2006).

In addition to the above BDNF-TrkB signaling effects, blocking $\mathrm{A}_{2 a} \mathrm{Rs}$, which co-localize with and directly transactivate TrkB, protected cultured MNs from these detrimental effects (Mojsilovic-Petrovic et al., 2005, 2006; Ng et al., 2015; Cunha, 2016). Similarly the inhibition of TrkB or $A_{2 a}$ Rs also prevents toxicity following expression of the G85R or G37R SOD1 mutations, which are highly toxic to cultured MNs (MojsilovicPetrovic et al., 2006; Jeong et al., 2011). These pro-toxic effects of BDNF/TrkB are not merely an artifact of culturing embryonic MNs. It has also been shown that in vivo conditional deletion of TrkB in MNs of adult transgenic mice carrying a G85R SOD1 mutation attenuates SOD1 toxicity, resulting in extension of life span and motor function, slowing MN loss and causing persistence of neuromuscular junctions (Zhai et al., 2011). Furthermore, in a recent study utilizing SOD $1^{G 93 A}$ rats, phrenic motor neurons displayed an increased expression of BDNF and phosphorylated ERK at end stage disease, consistent with possibly increased BDNF function and basal protein levels (Nichols et al., 2017).

Hyper-activity induced activation of BDNF and TrkB have also been observed in other disease states, such as epilepsy and traumatic brain injury (Dai et al., 2010; Iughetti et al., 2018). 
Upregulated expression of BDNF and TrkB has been well documented, resulting in alteration of excitability and neuronal network activity contributing to epileptogenesis (Scharfman, 1997; Iughetti et al., 2018). Enhancing BDNF expression or its systemic administration enhanced seizure activity in mice (Croll et al., 1999; Scharfman et al., 2002; Iughetti et al., 2018), while inhibiting TrkB reduced seizure development in these animals (Heinrich et al., 2011; Liu et al., 2014; Iughetti et al., 2018). Additionally, genetic or pharmacological inhibition of $\mathrm{A}_{2 a} \mathrm{Rs}$ in epilepsy has been shown to reduce seizures and neuronal damage (El Yacoubi et al., 2008, 2009). Despite these numerous reports, the concept of hyper-activity induced glutamate excitotoxicity resulting in overexpression of BDNF and TrkB activation in neuronal death still needs further investigation.

\section{CONCLUSION}

Amyotrophic lateral sclerosis is an incurable multi-factorial disease state where synaptic and intrinsic hyper-activity of MNs is a significant early factor (Mogyoros et al., 1998; Kanai et al., 2006; van Zundert et al., 2008; Fogarty et al., 2015). Therapeutic avenues until now have aimed at a reduction of this excitable state. Neuronal hyperactivity is plausibly a result of processes that take place simultaneously, one of them being the secretion of BDNF and activation of its receptor TrkB. Several lines of evidence show that increased BDNF-TrkB is evident in a number of

\section{REFERENCES}

Abe, K., Itoyama, Y., Sobue, G., Tsuji, S., Aoki, M., Doyu, M., et al. (2014). Confirmatory double-blind, parallel-group, placebo-controlled study of efficacy and safety of edaravone (MCI-186) in amyotrophic lateral sclerosis patients. Amyotroph. Lateral Scler. Frontotemporal Degener. 15, 610-617. doi: 10.3109/ 21678421.2014.959024

Adachi, N., Kohara, K., and Tsumoto, T. (2005). Difference in trafficking of brainderived neurotrophic factor between axons and dendrites of cortical neurons, revealed by live-cell imaging. BMC Neurosci. 6:42.

Aid, T., Kazantseva, A., Piirsoo, M., Palm, K., and Timmusk, T. (2007). Mouse and rat BDNF gene structure and expression revisited. J. Neurosci. Res. 85, 525-535. doi: $10.1002 /$ jnr.21139

Alcantara, S., Frisen, J., Del Rio, J. A., Soriano, E., Barbacid, M., and Silos-Santiago, I. (1997). TrkB signaling is required for postnatal survival of CNS neurons and protects hippocampal and motor neurons from axotomy-induced cell death. J. Neurosci. 17, 3623-3633. doi: 10.1523/jneurosci.17-10-03623.1997

An, J. J., Gharami, K., Liao, G. Y., Woo, N. H., Lau, A. G., Vanevski, F., et al. (2008). Distinct role of long 3' UTR BDNF mRNA in spine morphology and synaptic plasticity in hippocampal neurons. Cell 134, 175-187. doi: 10.1016/j.cell.2008. 05.045

Anastasia, A., Deinhardt, K., Chao, M. V., Will, N. E., Irmady, K., Lee, F. S., et al. (2013). Val66Met polymorphism of BDNF alters prodomain structure to induce neuronal growth cone retraction. Nat. Commun. 4:2490. doi: 10.1038/ ncomms 3490

Andreae, L. C., and Burrone, J. (2018). The role of spontaneous neurotransmission in synapse and circuit development. J. Neurosci. Res. 96, 354-359. doi: 10.1002/ jnr. 24154

Aytan, N., Choi, J. K., Carreras, I., Crabtree, L., Nguyen, B., Lehar, M., et al. (2018). Protective effects of 7,8-dihydroxyflavone on neuropathological and neurochemical changes in a mouse model of Alzheimer's disease. Eur. J. Pharmacol. 828, 9-17. doi: 10.1016/j.ejphar.2018.02.045 neurodegenerative diseases, including ALS (Kust et al., 2002; $\mathrm{Hu}$ and Kalb, 2003; Nichols et al., 2017). This suggests that neuronal damage may be a result of excessive rather than a shortage of, neurotrophic support. A broader understanding of the factors that regulate altered neuronal activity and BDNF could help to identify new therapeutic targets in neurodegenerative diseases. Certainly, therapies that enhance endogenous BDNF have failed to produce any success in prevention or slowing of $\mathrm{MN}$ death in ALS. It is important to further investigate both pro- and anti-trophic functions of $\mathrm{BDNF} / \mathrm{TrkB}$ in the hope of discovering novel therapeutic avenues to alleviate this devastating disease and other neurodegenerative conditions.

\section{AUTHOR CONTRIBUTIONS}

All authors contributed to the writing and editing of the manuscript.

\section{FUNDING}

This research was supported by an International Postgraduate Scholarship from the University of Queensland to JP, funding from the National Health and Medical Research Council to MB and PN (APP1065884), and funding from the Motor Neuron Disease Research Institute of Australia to MB.

Azdad, K., Gall, D., Woods, A. S., Ledent, C., Ferre, S., and Schiffmann, S. N. (2009). Dopamine D2 and adenosine A2A receptors regulate NMDA-mediated excitation in accumbens neurons through A2A-D2 receptor heteromerization. Neuropsychopharmacology 34, 972-986. doi: 10.1038/npp.2008.144

Bae, J. S., Simon, N. G., Menon, P., Vucic, S., and Kiernan, M. C. (2013). The puzzling case of hyperexcitability in amyotrophic lateral sclerosis. J. Clin. Neurol. 9, 65-74. doi: 10.3988/jcn.2013.9.2.65

Balkowiec, A., and Katz, D. M. (2002). Cellular mechanisms regulating activity-dependent release of native brain-derived neurotrophic factor from hippocampal neurons. J. Neurosci. 22, 10399-10407. doi: 10.1523/jneurosci.2223-10399.2002

Barde, Y. A., Edgar, D., and Thoenen, H. (1982). Purification of a new neurotrophic factor from mammalian brain. Embo J. 1, 549-553. doi: 10.1002/j.1460-2075. 1982.tb01207.x

Bartel, D. P. (2004). MicroRNAs: genomics, biogenesis, mechanism, and function. Cell 116, 281-297.

Baxter, G. T., Radeke, M. J., Kuo, R. C., Makrides, V., Hinkle, B., Hoang, R., et al. (1997). Signal transduction mediated by the truncated trkB receptor isoforms, trkB.T1 and trkB.T2. J. Neurosci. 17, 2683-2690. doi: 10.1523/jneurosci.17-0802683.1997

Begni, V., Riva, M. A., and Cattaneo, A. (2017). Cellular and molecular mechanisms of the brain-derived neurotrophic factor in physiological and pathological conditions. Clin. Sci. 131, 123-138. doi: 10.1042/cs20160009

Bellingham, M. C. (2013a). "Pharmacological dissection of G protein-mediated second messenger cascades in neurons," in Stimulation and Inhibition of Neurons, eds P. M. Pilowsky, M. M. J. Farnham, and A. Y. Fong (Totowa, NJ: Humana Press), 61-106. doi: 10.1007/978-1-62703-233-9_5

Bellingham, M. C. (2013b). Pre- and postsynaptic mechanisms underlying inhibition of hypoglossal motor neuron excitability by riluzole. J. Neurophysiol. 110, 1047-1061. doi: 10.1152/jn.00587.2012

Bemelmans, A. P., Husson, I., Jaquet, M., Mallet, J., Kosofsky, B. E., and Gressens, P. (2006). Lentiviral-mediated gene transfer of brain-derived neurotrophic 
factor is neuroprotective in a mouse model of neonatal excitotoxic challenge. J. Neurosci. Res. 83, 50-60. doi: 10.1002/jnr.20704

Bensimon, G., Lacomblez, L., and Meininger, V. (1994). A controlled trial of riluzole in amyotrophic lateral sclerosis. ALS/Riluzole study group. N. Engl. J. Med. 330, 585-591.

Blochl, A., and Thoenen, H. (1995). Characterization of nerve growth factor (NGF) release from hippocampal neurons: evidence for a constitutive and an unconventional sodium-dependent regulated pathway. Eur. J. Neurosci. 7, 1220-1228. doi: 10.1111/j.1460-9568.1995.tb01112.x

Blum, R., Kafitz, K. W., and Konnerth, A. (2002). Neurotrophin-evoked depolarization requires the sodium channel $\mathrm{Na}(\mathrm{V}) 1.9$. Nature 419, 687-693. doi: $10.1038 /$ nature 01085

Bostock, H., Cikurel, K., and Burke, D. (1998). Threshold tracking techniques in the study of human peripheral nerve. Muscle Nerve 21, 137-158. doi: 10.1002/ (sici)1097-4598(199802)21:2<137::aid-mus1>3.0.co;2-c

Boulenguez, P., Liabeuf, S., Bos, R., Bras, H., Jean-Xavier, C., Brocard, C., et al. (2010). Down-regulation of the potassium-chloride cotransporter KCC2 contributes to spasticity after spinal cord injury. Nat. Med. 16, 302-307. doi: $10.1038 / \mathrm{nm} .2107$

Bradley, J., and Sporns, O. (1999). BDNF-dependent enhancement of exocytosis in cultured cortical neurons requires translation but not transcription. Brain Res. 815, 140-149. doi: 10.1016/s0006-8993(98)01112-3

Brigadski, T., Hartmann, M., and Lessmann, V. (2005). Differential vesicular targeting and time course of synaptic secretion of the mammalian neurotrophins. J. Neurosci. 25, 7601-7614. doi: 10.1523/jneurosci.177605.2005

Brites, D., and Vaz, A. R. (2014). Microglia centered pathogenesis in ALS: insights in cell interconnectivity. Front. Cell. Neurosci. 8:117. doi: 10.3389/fncel.2014. 00117

Bronfman, F. C., and Fainzilber, M. (2004). Multi-tasking by the p75 neurotrophin receptor: sortilin things out? EMBO Rep. 5, 867-871. doi: 10.1038/sj.embor. 7400219

Brown, R. H., and Al-Chalabi, A. (2017). Amyotrophic lateral sclerosis. N. Engl. J. Med. 377, 162-172.

Brunet, A., Datta, S. R., and Greenberg, M. E. (2001). Transcription-dependent and -independent control of neuronal survival by the PI3K-Akt signaling pathway. Curr. Opin. Neurobiol. 11, 297-305. doi: 10.1016/s0959-4388(00)00 211-7

Canossa, M., Griesbeck, O., Berninger, B., Campana, G., Kolbeck, R., and Thoenen, H. (1997). Neurotrophin release by neurotrophins: implications for activitydependent neuronal plasticity. Proc. Natl. Acad. Sci. U.S.A. 94, 13279-13286. doi: $10.1073 /$ pnas.94.24.13279

Carim-Todd, L., Bath, K. G., Fulgenzi, G., Yanpallewar, S., Jing, D., Barrick, C. A., et al. (2009). Endogenous truncated TrkB.T1 receptor regulates neuronal complexity and TrkB kinase receptor function in vivo. J. Neurosci. 29, 678-685. doi: 10.1523/JNEUROSCI.5060-08.2009

Carter, A. R., Chen, C., Schwartz, P. M., and Segal, R. A. (2002). Brain-derived neurotrophic factor modulates cerebellar plasticity and synaptic ultrastructure. J. Neurosci. 22, 1316-1327. doi: 10.1523/jneurosci.22-04-01316.2002

Chao, M. V. (2003). Neurotrophins and their receptors: a convergence point for many signalling pathways. Nat. Rev. Neurosci. 4, 299-309. doi: 10.1038/ nrn 1078

Chao, M. V., and Hempstead, B. L. (1995). p75 and Trk: a two-receptor system. Trends Neurosci. 18, 321-326. doi: 10.1016/0166-2236(95)93922-k

Chico, L., Modena, M., Lo Gerfo, A., Ricci, G., Caldarazzo Ienco, E., Ryskalin, L., et al. (2017). Cross-talk between pathogenic mechanisms in neurodegeneration: the role of oxidative stress in amyotrophic lateral sclerosis. Arch. Ital. Biol. 155, 131-141. doi: 10.12871/00039829201744

Chio, A., Calvo, A., Mazzini, L., Cantello, R., Mora, G., Moglia, C., et al. (2012). Extensive genetics of ALS: a population-based study in Italy. Neurology 79, 1983-1989. doi: 10.1212/wnl.0b013e3182735d36

Ciruela, F., Albergaria, C., Soriano, A., Cuffi, L., Carbonell, L., Sanchez, S., et al. (2010). Adenosine receptors interacting proteins (ARIPs): behind the biology of adenosine signaling. Biochim. Biophys. Acta 1798, 9-20. doi: 10.1016/j.bbamem. 2009.10.016

Cleveland, D. W., and Rothstein, J. D. (2001). From Charcot to Lou Gehrig: deciphering selective motor neuron death in ALS. Nat. Rev. Neurosci. 2, 806819. doi: $10.1038 / 35097565$
Coull, J. A., Beggs, S., Boudreau, D., Boivin, D., Tsuda, M., Inoue, K., et al. (2005). BDNF from microglia causes the shift in neuronal anion gradient underlying neuropathic pain. Nature 438, 1017-1021. doi: 10.1038/nature04223

Croll, S. D., Suri, C., Compton, D. L., Simmons, M. V., Yancopoulos, G. D., Lindsay, R. M., et al. (1999). Brain-derived neurotrophic factor transgenic mice exhibit passive avoidance deficits, increased seizure severity and in vitro hyperexcitability in the hippocampus and entorhinal cortex. Neuroscience 93, 1491-1506. doi: 10.1016/s0306-4522(99)00296-1

Cunha, C., Brambilla, R., and Thomas, K. L. (2010). A simple role for BDNF in learning and memory? Front. Mol. Neurosci. 3:1. doi: 10.3389/neuro.02.001. 2010

Cunha, R. A. (2016). How does adenosine control neuronal dysfunction and neurodegeneration? J. Neurochem. 139, 1019-1055. doi: 10.1111/jnc.13724

Dai, S. S., Zhou, Y. G., Li, W., An, J. H., Li, P., Yang, N., et al. (2010). Local glutamate level dictates adenosine $\mathrm{A} 2 \mathrm{~A}$ receptor regulation of neuroinflammation and traumatic brain injury. J. Neurosci. 30, 5802-5810. doi: 10.1523/JNEUROSCI. 0268- 10.2010

Deinhardt, K., and Chao, M. V. (2014). Shaping neurons: long and short range effects of mature and proBDNF signalling upon neuronal structure. Neuropharmacology 76(Pt C), 603-609. doi: 10.1016/j.neuropharm.2013.04. 054

DeJesus-Hernandez, M., Mackenzie, I. R., Boeve, B. F., Boxer, A. L., Baker, M., Rutherford, N. J., et al. (2011). Expanded GGGGCC hexanucleotide repeat in noncoding region of C9ORF72 causes chromosome 9p-linked FTD and ALS. Neuron 72, 245-256. doi: 10.1016/j.neuron.2011.09.011

Dieni, S., Matsumoto, T., Dekkers, M., Rauskolb, S., Ionescu, M. S., Deogracias, R., et al. (2012). BDNF and its pro-peptide are stored in presynaptic dense core vesicles in brain neurons. J. Cell Biol. 196, 775-788. doi: 10.1083/jcb.201201038

Diogenes, M. J., Fernandes, C. C., Sebastiao, A. M., and Ribeiro, J. A. (2004) Activation of adenosine A2A receptor facilitates brain-derived neurotrophic factor modulation of synaptic transmission in hippocampal slices. J. Neurosci. 24, 2905-2913. doi: 10.1523/jneurosci.4454-03.2004

Du, J., Feng, L., Zaitsev, E., Je, H. S., Liu, X. W., and Lu, B. (2003). Regulation of TrkB receptor tyrosine kinase and its internalization by neuronal activity and Ca2+ influx. J. Cell Biol. 163, 385-395. doi: 10.1083/jcb.200305134

Egan, M. F., Kojima, M., Callicott, J. H., Goldberg, T. E., Kolachana, B. S., Bertolino, A., et al. (2003). The BDNF val66met polymorphism affects activity-dependent secretion of BDNF and human memory and hippocampal function. Cell 112, 257-269. doi: 10.1016/s0092-8674(03)00035-7

El Yacoubi, M., Ledent, C., Parmentier, M., Costentin, J., and Vaugeois, J. M. (2008). Evidence for the involvement of the adenosine A(2A) receptor in the lowered susceptibility to pentylenetetrazol-induced seizures produced in mice by longterm treatment with caffeine. Neuropharmacology 55, 35-40. doi: 10.1016/j. neuropharm.2008.04.007

El Yacoubi, M., Ledent, C., Parmentier, M., Costentin, J., and Vaugeois, J. M. (2009). Adenosine A2A receptor deficient mice are partially resistant to limbic seizures. Naunyn Schmiedebergs Arch. Pharmacol. 380, 223-232. doi: 10.1007/s00210009-0426-8

Fang, T., Al Khleifat, A., Meurgey, J. H., Jones, A., Leigh, P. N., Bensimon, G., et al. (2018). Stage at which riluzole treatment prolongs survival in patients with amyotrophic lateral sclerosis: a retrospective analysis of data from a dose-ranging study. Lancet Neurol. 17, 416-422. doi: 10.1016/S1474-4422(18) 30054-1

Fenner, B. M. (2012). Truncated TrkB: beyond a dominant negative receptor. Cytokine Growth Factor Rev. 23, 15-24. doi: 10.1016/j.cytogfr.2012.01.002

Ferrini, F., and De Koninck, Y. (2013). Microglia control neuronal network excitability via BDNF signalling. Neural Plast. 2013:429815. doi: 10.1155/2013/ 429815

Fiumelli, H., and Woodin, M. A. (2007). Role of activity-dependent regulation of neuronal chloride homeostasis in development. Curr. Opin. Neurobiol. 17, 81-86. doi: 10.1016/j.conb.2007.01.002

Fogarty, M. J., Mu, E. W., Noakes, P. G., Lavidis, N. A., and Bellingham, M. C. (2016). Marked changes in dendritic structure and spine density precede significant neuronal death in vulnerable cortical pyramidal neuron populations in the SOD1(G93A) mouse model of amyotrophic lateral sclerosis. Acta Neuropathol. Commun. 4:77. doi: 10.1186/s40478-016-0347-y

Fogarty, M. J., Noakes, P. G., and Bellingham, M. C. (2015). Motor cortex layer $\mathrm{V}$ pyramidal neurons exhibit dendritic regression, spine loss, and 
increased synaptic excitation in the presymptomatic hSOD1(G93A) mouse model of amyotrophic lateral sclerosis. J. Neurosci. 35, 643-647. doi: 10.1523/ JNEUROSCI.3483-14.2015

Foltran, R. B., and Diaz, S. L. (2016). BDNF isoforms: a round trip ticket between neurogenesis and serotonin? J. Neurochem. 138, 204-221. doi: 10.1111/jnc. 13658

Fryer, H. J., Knox, R. J., Strittmatter, S. M., and Kalb, R. G. (1999). Excitotoxic death of a subset of embryonic rat motor neurons in vitro. J. Neurochem. 72, 500-513. doi: 10.1046/j.1471-4159.1999.0720500.x

Fryer, H. J., Wolf, D. H., Knox, R. J., Strittmatter, S. M., Pennica, D., O’leary, R. M., et al. (2000). Brain-derived neurotrophic factor induces excitotoxic sensitivity in cultured embryonic rat spinal motor neurons through activation of the phosphatidylinositol 3-kinase pathway. J. Neurochem. 74, 582-595. doi: 10.1046/j.1471-4159.2000.740582.x

Fryer, R. H., Kaplan, D. R., Feinstein, S. C., Radeke, M. J., Grayson, D. R., and Kromer, L. F. (1996). Developmental and mature expression of fulllength and truncated TrkB receptors in the rat forebrain. J. Comp. Neurol. 374, 21-40. doi: 10.1002/(sici)1096-9861(19961007)374:1<21::aid-cne2>3. $0 . \mathrm{co} ; 2-\mathrm{p}$

Fryer, R. H., Kaplan, D. R., and Kromer, L. F. (1997). Truncated trkB receptors on nonneuronal cells inhibit BDNF-induced neurite outgrowth in vitro. Exp. Neurol. 148, 616-627. doi: 10.1006/exnr.1997.6699

Fuchs, A., Ringer, C., Bilkei-Gorzo, A., Weihe, E., Roeper, J., and Schutz, B. (2010). Downregulation of the potassium chloride cotransporter KCC2 in vulnerable motoneurons in the SOD1-G93A mouse model of amyotrophic lateral sclerosis. J. Neuropathol. Exp. Neurol. 69, 1057-1070. doi: 10.1097/NEN. 0b013e3181f4dcef

Gomes, R. A., Hampton, C., El-Sabeawy, F., Sabo, S. L., and Mcallister, A. K. (2006). The dynamic distribution of TrkB receptors before, during, and after synapse formation between cortical neurons. J. Neurosci. 26, 11487-11500. doi: 10.1523/jneurosci.2364-06.2006

Gonzalez, A., Moya-Alvarado, G., Gonzalez-Billaut, C., and Bronfman, F. C. (2016). Cellular and molecular mechanisms regulating neuronal growth by brain-derived neurotrophic factor. Cytoskeleton 73, 612-628. doi: 10.1002/cm. 21312

Goodman, C. S., and Shatz, C. J. (1993). Developmental mechanisms that generate precise patterns of neuronal connectivity. Cell 72(Suppl.), 77-98. doi: 10.1016/ s0092-8674(05)80030-3

Goodman, L. J., Valverde, J., Lim, F., Geschwind, M. D., Federoff, H. J., Geller, A. I., et al. (1996). Regulated release and polarized localization of brain-derived neurotrophic factor in hippocampal neurons. Mol. Cell. Neurosci. 7, 222-238. doi: 10.1006/mcne.1996.0017

Griesbeck, O., Canossa, M., Campana, G., Gartner, A., Hoener, M. C., Nawa, H., et al. (1999). Are there differences between the secretion characteristics of NGF and BDNF? Implications for the modulatory role of neurotrophins in activity-dependent neuronal plasticity. Microsc. Res. Tech. 45, 262-275. doi: 10.1002/(sici)1097-0029(19990515/01)45:4/5<262::aid-jemt10>3.0.co;2-k

Guerzoni, L. P., Nicolas, V., and Angelova, A. (2017). In Vitro modulation of TrkB receptor signaling upon sequential delivery of curcumin-DHA loaded carriers towards promoting neuronal survival. Pharm. Res. 34, 492-505. doi: 10.1007/s11095-016-2080-4

Guo, J., Ji, Y., Ding, Y., Jiang, W., Sun, Y., Lu, B., et al. (2016). BDNF propeptide regulates dendritic spines via caspase-3. Cell Death Dis. 7:e2264. doi: $10.1038 /$ cddis.2016.166

Gurney, M. E., Pu, H., Chiu, A. Y., Dal Canto, M. C., Polchow, C. Y., Alexander, D. D., et al. (1994). Motor neuron degeneration in mice that express a human $\mathrm{Cu}, \mathrm{Zn}$ superoxide dismutase mutation. Science 264, 1772-1775. doi: 10.1126/ science. 8209258

Hartmann, M., Heumann, R., and Lessmann, V. (2001). Synaptic secretion of BDNF after high-frequency stimulation of glutamatergic synapses. EMBO J. 20, 5887-5897. doi: 10.1093/emboj/20.21.5887

Hayashi, Y., Homma, K., and Ichijo, H. (2016). SOD1 in neurotoxicity and its controversial roles in SOD1 mutation-negative ALS. Adv. Biol. Regul. 60, 95-104. doi: 10.1016/j.jbior.2015.10.006

Heinrich, C., Lahteinen, S., Suzuki, F., Anne-Marie, L., Huber, S., Haussler, U., et al. (2011). Increase in BDNF-mediated TrkB signaling promotes epileptogenesis in a mouse model of mesial temporal lobe epilepsy. Neurobiol. Dis. 42, 35-47. doi: 10.1016/j.nbd.2011.01.001
Hempstead, B. L. (2015). Brain-derived neurotrophic factor: three ligands, many actions. Trans. Am. Clin. Climatol. Assoc. 126, 9-19.

Henriques, A., Pitzer, C., and Schneider, A. (2010). Neurotrophic growth factors for the treatment of amyotrophic lateral sclerosis: where do we stand? Front. Neurosci. 4:32. doi: 10.3389/fnins.2010.00032

Higley, M. J., and Sabatini, B. L. (2010). Competitive regulation of synaptic Ca2+ influx by D2 dopamine and A2A adenosine receptors. Nat. Neurosci. 13, 958-966. doi: 10.1038/nn.2592

Hong, E. J., Mccord, A. E., and Greenberg, M. E. (2008). A biological function for the neuronal activity-dependent component of Bdnf transcription in the development of cortical inhibition. Neuron 60, 610-624. doi: 10.1016/j.neuron. 2008.09.024

Hu, P., and Kalb, R. G. (2003). BDNF heightens the sensitivity of motor neurons to excitotoxic insults through activation of TrkB. J. Neurochem. 84, 1421-1430. doi: 10.1046/j.1471-4159.2003.01599.x

Huang, E. J., and Reichardt, L. F. (2001). Neurotrophins: roles in neuronal development and function. Annu. Rev. Neurosci. 24, 677-736. doi: 10.1146/ annurev.neuro.24.1.677

Huang, E. J., and Reichardt, L. F. (2003). Trk receptors: roles in neuronal signal transduction. Annu. Rev. Biochem. 72, 609-642. doi: 10.1146/annurev.biochem. 72.121801 .161629

Huang, Y. Z., Pan, E., Xiong, Z. Q., and Mcnamara, J. O. (2008). Zinc-mediated transactivation of TrkB potentiates the hippocampal mossy fiber-CA3 pyramid synapse. Neuron 57, 546-558. doi: 10.1016/j.neuron.2007.11.026

Hwang, J. J., Park, M. H., Choi, S. Y., and Koh, J. Y. (2005). Activation of the Trk signaling pathway by extracellular zinc. Role of metalloproteinases. J. Biol. Chem. 280, 11995-12001. doi: 10.1074/jbc.m403172200

Ishikawa, Y., Ikeuchi, T., and Hatanaka, H. (2000). Brain-derived neurotrophic factor accelerates nitric oxide donor-induced apoptosis of cultured cortical neurons. J. Neurochem. 75, 494-502. doi: 10.1046/j.1471-4159.2000.0750494.x

Iughetti, L., Lucaccioni, L., Fugetto, F., Predieri, B., Berardi, A., and Ferrari, F. (2018). Brain-derived neurotrophic factor and epilepsy: a systematic review. Neuropeptides 72, 23-29. doi: 10.1016/j.npep.2018.09.005

Iwakura, Y., Nawa, H., Sora, I., and Chao, M. V. (2008). Dopamine D1 receptorinduced signaling through TrkB receptors in striatal neurons. J. Biol. Chem. 283, 15799-15806. doi: 10.1074/jbc.M801553200

Jacobson, K. A., and Gao, Z. G. (2006). Adenosine receptors as therapeutic targets. Nat. Rev. Drug Discov. 5, 247-264.

Jeong, G. B., Mojsilovic-Petrovic, J., Boccitto, M., and Kalb, R. (2011). Signaling events in axons and/or dendrites render motor neurons vulnerable to mutant superoxide dismutase toxicity. J. Neurosci. 31, 295-299. doi: 10.1523/ JNEUROSCI.4824-10.2011

Ji, Y., Lu, Y., Yang, F., Shen, W., Tang, T. T., Feng, L., et al. (2010). Acute and gradual increases in BDNF concentration elicit distinct signaling and functions in neurons. Nat. Neurosci. 13, 302-309. doi: 10.1038/nn.2505

Jovanovic, J. N., Czernik, A. J., Fienberg, A. A., Greengard, P., and Sihra, T. S. (2000). Synapsins as mediators of BDNF-enhanced neurotransmitter release. Nat. Neurosci. 3, 323-329. doi: 10.1038/73888

Just-Borras, L., Hurtado, E., Cilleros-Mane, V., Biondi, O., Charbonnier, F., Tomas, M., et al. (2019). Overview of impaired BDNF signaling, their coupled downstream serine-threonine kinases and SNARE/SM complex in the neuromuscular junction of the amyotrophic lateral sclerosis model SOD1G93A mice. Mol. Neurobiol. [Epub ahead of print].

Kafitz, K. W., Rose, C. R., Thoenen, H., and Konnerth, A. (1999). Neurotrophinevoked rapid excitation through TrkB receptors. Nature 401, 918-921. doi: 10.1038/44847

Kanai, K., Kuwabara, S., Misawa, S., Tamura, N., Ogawara, K., Nakata, M., et al. (2006). Altered axonal excitability properties in amyotrophic lateral sclerosis: impaired potassium channel function related to disease stage. Brain 129, 953962. doi: 10.1093/brain/awl024

Kang, H., and Schuman, E. M. (1995). Long-lasting neurotrophin-induced enhancement of synaptic transmission in the adult hippocampus. Science 267, 1658-1662. doi: 10.1126/science.7886457

Kang, H., Welcher, A. A., Shelton, D., and Schuman, E. M. (1997). Neurotrophins and time: different roles for TrkB signaling in hippocampal long-term potentiation. Neuron 19, 653-664. doi: 10.1016/s0896-6273(00)80378-5

Kim, H. J., Hwang, J. J., Behrens, M. M., Snider, B. J., Choi, D. W., and Koh, J. Y. (2003). TrkB mediates BDNF-induced potentiation of neuronal necrosis 
in cortical culture. Neurobiol. Dis. 14, 110-119. doi: 10.1016/s0969-9961(03) 00103-7

King, A. E., Woodhouse, A., Kirkcaldie, M. T., and Vickers, J. C. (2016). Excitotoxicity in ALS: overstimulation, or overreaction? Exp. Neurol. 275(Pt 1), 162-171. doi: 10.1016/j.expneurol.2015.09.019

Klein, R., Smeyne, R. J., Wurst, W., Long, L. K., Auerbach, B. A., Joyner, A. L., et al. (1993). Targeted disruption of the trkB neurotrophin receptor gene results in nervous system lesions and neonatal death. Cell 75, 113-122. doi: 10.1016/ 0092-8674(93)90683-h

Koh, J. Y., Gwag, B. J., Lobner, D., and Choi, D. W. (1995). Potentiated necrosis of cultured cortical neurons by neurotrophins. Science 268, 573-575. doi: 10.1126/science.7725105

Kohara, K., Kitamura, A., Morishima, M., and Tsumoto, T. (2001). Activitydependent transfer of brain-derived neurotrophic factor to postsynaptic neurons. Science 291, 2419-2423. doi: 10.1126/science.1057415

Komaki, S., Ishikawa, K., and Arakawa, Y. (2012). Trk and cAMP-dependent survival activity of adenosine A(2A) agonist CGS21680 on rat motoneurons in culture. Neurosci. Lett. 522, 21-24. doi: 10.1016/j.neulet.2012.06.003

Korkmaz, O. T., Aytan, N., Carreras, I., Choi, J. K., Kowall, N. W., Jenkins, B. G., et al. (2014). 7,8-Dihydroxyflavone improves motor performance and enhances lower motor neuronal survival in a mouse model of amyotrophic lateral sclerosis. Neurosci. Lett. 566, 286-291. doi: 10.1016/j.neulet.2014.02.058

Kowianski, P., Lietzau, G., Czuba, E., Waskow, M., Steliga, A., and Morys, J. (2018). BDNF: a key factor with multipotent impact on brain signaling and synaptic plasticity. Cell Mol. Neurobiol. 38, 579-593. doi: 10.1007/s10571-017-0510-4

Kust, B. M., Copray, J. C., Brouwer, N., Troost, D., and Boddeke, H. W. (2002). Elevated levels of neurotrophins in human biceps brachii tissue of amyotrophic lateral sclerosis. Exp. Neurol. 177, 419-427. doi: 10.1006/exnr.2002.8011

Kutsarova, E., Munz, M., and Ruthazer, E. S. (2016). Rules for shaping neural connections in the developing brain. Front. Neural. Circuits 10:111. doi: 10. 3389/fncir.2016.00111

Lau, A. G., Irier, H. A., Gu, J., Tian, D., Ku, L., Liu, G., et al. (2010). Distinct 3'UTRs differentially regulate activity-dependent translation of brain-derived neurotrophic factor (BDNF). Proc. Natl. Acad. Sci. U.S.A. 107, 15945-15950. doi: $10.1073 /$ pnas. 1002929107

Le Masson, G., Przedborski, S., and Abbott, L. F. (2014). A computational model of motor neuron degeneration. Neuron 83, 975-988. doi: 10.1016/j.neuron.2014. 07.001

Leal, G., Afonso, P. M., Salazar, I. L., and Duarte, C. B. (2015). Regulation of hippocampal synaptic plasticity by BDNF. Brain Res. 1621, 82-101. doi: 10. 1016/j.brainres.2014.10.019

Lee, F. S., and Chao, M. V. (2001). Activation of Trk neurotrophin receptors in the absence of neurotrophins. Proc. Natl. Acad. Sci. U.S.A. 98, 3555-3560. doi: 10.1073/pnas.061020198

Lee-Hotta, S., Uchiyama, Y., and Kametaka, S. (2019). Role of the BDNF-TrkB pathway in KCC2 regulation and rehabilitation following neuronal injury: a mini review. Neurochem. Int. 128, 32-38. doi: 10.1016/j.neuint.2019.04.003

Lessmann, V. (1998). Neurotrophin-dependent modulation of glutamatergic synaptic transmission in the mammalian CNS. Gen. Pharmacol. 31, 667-674. doi: 10.1016/s0306-3623(98)00190-6

Lessmann, V., Gottmann, K., and Malcangio, M. (2003). Neurotrophin secretion: current facts and future prospects. Prog. Neurobiol. 69, 341-374. doi: 10.1016/ s0301-0082(03)00019-4

Levine, E. S., Dreyfus, C. F., Black, I. B., and Plummer, M. R. (1995). Brain-derived neurotrophic factor rapidly enhances synaptic transmission in hippocampal neurons via postsynaptic tyrosine kinase receptors. Proc. Natl. Acad. Sci. U.S.A 92, 8074-8077. doi: 10.1073/pnas.92.17.8074

Li, W., and Keifer, J. (2009). BDNF-induced synaptic delivery of AMPAR subunits is differentially dependent on NMDA receptors and requires ERK. Neurobiol. Learn. Mem. 91, 243-249. doi: 10.1016/j.nlm.2008.10.002

Liu, G., Kotloski, R. J., and Mcnamara, J. O. (2014). Antiseizure effects of TrkB kinase inhibition. Epilepsia 55, 1264-1273. doi: 10.1111/epi.12671

Lu, B. (2003). BDNF and activity-dependent synaptic modulation. Learn. Mem. 10, 86-98. doi: 10.1101/lm.54603

Lu, B., Pang, P. T., and Woo, N. H. (2005). The yin and yang of neurotrophin action. Nat. Rev. Neurosci. 6, 603-614. doi: 10.1038/nrn1726

Luberg, K., Wong, J., Weickert, C. S., and Timmusk, T. (2010). Human TrkB gene: novel alternative transcripts, protein isoforms and expression pattern in the prefrontal cerebral cortex during postnatal development. J. Neurochem. 113, 952-964. doi: 10.1111/j.1471-4159.2010.06662.x

Maki, T., Arishima, K., Yamamoto, M., and Sakaue, M. (2015). TrkB is involved in the mechanism by which BDNF accelerates the glutamate-induced death of rat neuroblastoma B35 cells. Neurol. Res. 37, 30-34. doi: 10.1179/1743132814Y. 0000000403

Marin, B., Boumediene, F., Logroscino, G., Couratier, P., Babron, M. C., Leutenegger, A. L., et al. (2017). Variation in worldwide incidence of amyotrophic lateral sclerosis: a meta-analysis. Int. J. Epidemiol. 46, 57-74. doi: 10.1093/ije/dyw061

Martinez, A., Alcantara, S., Borrell, V., Del Rio, J. A., Blasi, J., Otal, R., et al. (1998). $\operatorname{TrkB}$ and TrkC signaling are required for maturation and synaptogenesis of hippocampal connections. J. Neurosci. 18, 7336-7350. doi: 10.1523/jneurosci. 18-18-07336.1998

Mattson, M. P. (2008). Glutamate and neurotrophic factors in neuronal plasticity and disease. Ann. N. Y. Acad. Sci. 1144, 97-112. doi: 10.1196/annals. 1418.005

McAllister, A. K., Katz, L. C., and Lo, D. C. (1996). Neurotrophin regulation of cortical dendritic growth requires activity. Neuron 17, 1057-1064. doi: 10.1016/ s0896-6273(00)80239-1

Mellios, N., Huang, H. S., Grigorenko, A., Rogaev, E., and Akbarian, S. (2008). A set of differentially expressed miRNAs, including miR-30a-5p, act as posttranscriptional inhibitors of BDNF in prefrontal cortex. Hum. Mol. Genet. 17, 3030-3042. doi: 10.1093/hmg/ddn201

Middlemas, D. S., Lindberg, R. A., and Hunter, T. (1991). trkB, a neural receptor protein-tyrosine kinase: evidence for a full-length and two truncated receptors. Mol. Cell. Biol. 11, 143-153. doi: 10.1128/mcb.11.1.143

Minichiello, L., Calella, A. M., Medina, D. L., Bonhoeffer, T., Klein, R., and Korte, M. (2002). Mechanism of TrkB-mediated hippocampal long-term potentiation. Neuron 36, 121-137. doi: 10.1016/s0896-6273(02)00942-x

Mizoguchi, H., Nakade, J., Tachibana, M., Ibi, D., Someya, E., Koike, H., et al. (2011). Matrix metalloproteinase-9 contributes to kindled seizure development in pentylenetetrazole-treated mice by converting pro-BDNF to mature BDNF in the hippocampus. J. Neurosci. 31, 12963-12971. doi: 10.1523/JNEUROSCI. 3118-11.2011

Mizui, T., Ishikawa, Y., Kumanogoh, H., and Kojima, M. (2016). Neurobiological actions by three distinct subtypes of brain-derived neurotrophic factor: multiligand model of growth factor signaling. Pharmacol. Res. 105, 93-98. doi: 10. 1016/j.phrs.2015.12.019

Mogyoros, I., Kiernan, M. C., Burke, D., and Bostock, H. (1998). Strength-duration properties of sensory and motor axons in amyotrophic lateral sclerosis. Brain 121(Pt 5), 851-859. doi: 10.1093/brain/121.5.851

Mojsilovic-Petrovic, J., Arneja, A., and Kalb, R. G. (2005). Enprofylline protects motor neurons from in vitro excitotoxic challenge. Neurodegener. Dis. 2, $160-$ 165. doi: $10.1159 / 000089621$

Mojsilovic-Petrovic, J., Jeong, G. B., Crocker, A., Arneja, A., David, S., Russell, D. S., et al. (2006). Protecting motor neurons from toxic insult by antagonism of adenosine A2a and Trk receptors. J. Neurosci. 26, 9250-9263. doi: 10.1523/ jneurosci.1856-06.2006

Moreau, J. L., and Huber, G. (1999). Central adenosine A(2A) receptors: an overview. Brain Res. Brain Res. Rev. 31, 65-82. doi: 10.1016/s0165-0173(99) 00059-4

Murer, M. G., Yan, Q., and Raisman-Vozari, R. (2001). Brain-derived neurotrophic factor in the control human brain, and in Alzheimer's disease and Parkinson's disease. Prog. Neurobiol. 63, 71-124. doi: 10.1016/s0301-0082(00)00014-9

Nagappan, G., and Lu, B. (2005). Activity-dependent modulation of the BDNF receptor TrkB: mechanisms and implications. Trends Neurosci. 28, 464-471. doi: 10.1016/j.tins.2005.07.003

Nakagawara, A., Liu, X. G., Ikegaki, N., White, P. S., Yamashiro, D. J., Nycum, L. M., et al. (1995). Cloning and chromosomal localization of the human TRK-B tyrosine kinase receptor gene (NTRK2). Genomics 25, 538-546. doi: 10.1016/ 0888-7543(95)80055-q

Narisawa-Saito, M., Iwakura, Y., Kawamura, M., Araki, K., Kozaki, S., Takei, N., et al. (2002). Brain-derived neurotrophic factor regulates surface expression of alpha-amino-3-hydroxy-5-methyl-4-isoxazoleproprionic acid receptors by enhancing the N-ethylmaleimide-sensitive factor/GluR2 interaction in developing neocortical neurons. J. Biol. Chem. 277, 40901-40910. doi: $10.1074 /$ jbc.m202158200 
Ng, S. K., Higashimori, H., Tolman, M., and Yang, Y. (2015). Suppression of adenosine 2a receptor (A2aR)-mediated adenosine signaling improves disease phenotypes in a mouse model of amyotrophic lateral sclerosis. Exp. Neurol. 267, 115-122. doi: 10.1016/j.expneurol.2015.03.004

Nichols, N. L., Satriotomo, I., and Allen, L. L. (2017). Mechanisms of enhanced phrenic long-term facilitation in SOD1(G93A) rats. J. Neurosci. 37, 5834-5845. doi: 10.1523/JNEUROSCI.3680-16.2017

Notaras, M., and van den Buuse, M. (2018). Brain-derived neurotrophic factor (BDNF): novel insights into regulation and genetic variation. Neuroscientist [Epub ahead of print],

Ohira, K., Homma, K. J., Hirai, H., Nakamura, S., and Hayashi, M. (2006). TrkB$\mathrm{T} 1$ regulates the RhoA signaling and actin cytoskeleton in glioma cells. Biochem. Biophys. Res. Commun. 342, 867-874. doi: 10.1016/j.bbrc.2006.02.033

Pansarasa, O., Bordoni, M., Diamanti, L., Sproviero, D., Gagliardi, S., and Cereda, C. (2018). SOD1 in amyotrophic lateral sclerosis: "Ambivalent" behavior connected to the disease. Int. J. Mol. Sci 19:1345. doi: 10.3390/ijms19051345

Park, H., and Poo, M. M. (2013). Neurotrophin regulation of neural circuit development and function. Nat. Rev. Neurosci. 14, 7-23. doi: 10.1038/nrn3379

Pasinelli, P., and Brown, R. H. (2006). Molecular biology of amyotrophic lateral sclerosis: insights from genetics. Nat. Rev. Neurosci. 7, 710-723. doi: 10.1038/ nrn1971

Patapoutian, A., and Reichardt, L. F. (2001). Trk receptors: mediators of neurotrophin action. Curr. Opin. Neurobiol. 11, 272-280. doi: 10.1016/s09594388(00)00208-7

Pozzo-Miller, L. D., Gottschalk, W., Zhang, L., Mcdermott, K., Du, J., Gopalakrishnan, R., et al. (1999). Impairments in high-frequency transmission, synaptic vesicle docking, and synaptic protein distribution in the hippocampus of BDNF knockout mice. J. Neurosci. 19, 4972-4983. doi: 10.1523/jneurosci.1912-04972.1999

Pruunsild, P., Kazantseva, A., Aid, T., Palm, K., and Timmusk, T. (2007). Dissecting the human BDNF locus: bidirectional transcription, complex splicing, and multiple promoters. Genomics 90, 397-406. doi: 10.1016/j.ygeno.2007. 05.004

Puehringer, D., Orel, N., Luningschror, P., Subramanian, N., Herrmann, T., Chao, M. V., et al. (2013). EGF transactivation of Trk receptors regulates the migration of newborn cortical neurons. Nat. Neurosci. 16, 407-415. doi: 10.1038/nn.3333

Quarta, E., Fulgenzi, G., Bravi, R., Cohen, E. J., Yanpallewar, S., Tessarollo, L., et al. (2018). Deletion of the endogenous TrkB.T1 receptor isoform restores the number of hippocampal CA1 parvalbumin-positive neurons and rescues long-term potentiation in pre-symptomatic mSOD1(G93A) ALS mice. Mol. Cell Neurosci. 89, 33-41. doi: 10.1016/j.mcn.2018.03.010

Rao, V. R., and Finkbeiner, S. (2007). NMDA and AMPA receptors: old channels, new tricks. Trends Neurosci. 30, 284-291. doi: 10.1016/j.tins.2007.03.012

Reichardt, L. F. (2006). Neurotrophin-regulated signalling pathways. Philos. Trans. R. Soc. Lond. B Biol. Sci. 361, 1545-1564. doi: 10.1098/rstb.2006.1894

Righi, M., Tongiorgi, E., and Cattaneo, A. (2000). Brain-derived neurotrophic factor (BDNF) induces dendritic targeting of BDNF and tyrosine kinase B mRNAs in hippocampal neurons through a phosphatidylinositol-3 kinasedependent pathway. J. Neurosci. 20, 3165-3174. doi: 10.1523/jneurosci.20-0903165.2000

Ringholz, G. M., Appel, S. H., Bradshaw, M., Cooke, N. A., Mosnik, D. M., and Schulz, P. E. (2005). Prevalence and patterns of cognitive impairment in sporadic ALS. Neurology 65, 586-590. doi: 10.1212/01.wnl.0000172911. 39167.b6

Rivera, C., Li, H., Thomas-Crusells, J., Lahtinen, H., Viitanen, T., Nanobashvili, A., et al. (2002). BDNF-induced TrkB activation down-regulates the $\mathrm{K}+-\mathrm{Cl}-$ cotransporter KCC2 and impairs neuronal Cl- extrusion. J. Cell Biol. 159, 747-752. doi: 10.1083/jcb.200209011

Rivera, C., Voipio, J., Payne, J. A., Ruusuvuori, E., Lahtinen, H., Lamsa, K., et al. (1999). The K+/Cl- co-transporter KCC2 renders GABA hyperpolarizing during neuronal maturation. Nature 397, 251-255. doi: 10.1038/16697

Rivera, C., Voipio, J., Thomas-Crusells, J., Li, H., Emri, Z., Sipila, S., et al. (2004). Mechanism of activity-dependent downregulation of the neuron-specific K-Cl cotransporter KCC2. J. Neurosci. 24, 4683-4691. doi: 10.1523/jneurosci.526503.2004

Rose, C. R., Blum, R., Kafitz, K. W., Kovalchuk, Y., and Konnerth, A. (2004). From modulator to mediator: rapid effects of BDNF on ion channels. Bioessays 26, 1185-1194. doi: 10.1002/bies.20118
Rosen, D. R., Siddique, T., Patterson, D., Figlewicz, D. A., Sapp, P., Hentati, A., et al. (1993). Mutations in $\mathrm{Cu} / \mathrm{Zn}$ superoxide dismutase gene are associated with familial amyotrophic lateral sclerosis. Nature 362, 59-62.

Rothstein, J. D., Martin, L. J., and Kuncl, R. W. (1992). Decreased glutamate transport by the brain and spinal cord in amyotrophic lateral sclerosis. N. Engl. J. Med. 326, 1464-1468. doi: 10.1056/nejm199205283262204

Saba, L., Viscomi, M. T., Caioli, S., Pignataro, A., Bisicchia, E., Pieri, M., et al. (2016). Altered functionality, morphology, and vesicular glutamate transporter expression of cortical motor neurons from a presymptomatic mouse model of amyotrophic lateral sclerosis. Cereb. Cortex 26, 1512-1528. doi: 10.1093/cercor/ bhu317

Sandstedt, P., Littorin, S., Johansson, S., Gottberg, K., Ytterberg, C., and Kierkegaard, M. (2018). Disability and contextual factors in patients with amyotrophic lateral sclerosis - a three-year observational study. J. Neuromuscul. Dis. 5, 439-449. doi: 10.3233/JND- 180322

Sarantis, K., Tsiamaki, E., Kouvaros, S., Papatheodoropoulos, C., and Angelatou, F. (2015). Adenosine A(2)A receptors permit mGluR5-evoked tyrosine phosphorylation of NR2B (Tyr1472) in rat hippocampus: a possible key mechanism in NMDA receptor modulation. J. Neurochem. 135, 714-726. doi: 10.1111/jnc.13291

Sasi, M., Vignoli, B., Canossa, M., and Blum, R. (2017). Neurobiology of local and intercellular BDNF signaling. Pflugers Arch. 469, 593-610. doi: 10.1007/s00424017-1964-4

Scharfman, H. E. (1997). Hyperexcitability in combined entorhinal/hippocampal slices of adult rat after exposure to brain-derived neurotrophic factor. J. Neurophysiol. 78, 1082-1095. doi: 10.1152/jn.1997.78.2.1082

Scharfman, H. E., Goodman, J. H., Sollas, A. L., and Croll, S. D. (2002). Spontaneous limbic seizures after intrahippocampal infusion of brain-derived neurotrophic factor. Exp. Neurol. 174, 201-214. doi: 10.1006/exnr.2002.7869

Schneider, R., and Schweiger, M. (1991). A novel modular mosaic of cell adhesion motifs in the extracellular domains of the neurogenic trk and trkB tyrosine kinase receptors. Oncogene 6, 1807-1811.

Schratt, G. M., Nigh, E. A., Chen, W. G., Hu, L., and Greenberg, M. E. (2004). BDNF regulates the translation of a select group of mRNAs by a mammalian target of rapamycin-phosphatidylinositol 3-kinase-dependent pathway during neuronal development. J. Neurosci. 24, 7366-7377. doi: 10.1523/jneurosci. 1739-04.2004

Sebastiao, A. M., Rei, N., and Ribeiro, J. A. (2018). Amyotrophic lateral sclerosis (ALS) and adenosine receptors. Front. Pharmacol. 9:267. doi: 10.3389/fphar. 2018.00267

Sebastiao, A. M., and Ribeiro, J. A. (2009). Adenosine receptors and the central nervous system. Handb. Exp. Pharmacol. 193, 471-534. doi: 10.1007/978-3540-89615-9_16

Shaywitz, A. J., and Greenberg, M. E. (1999). CREB: a stimulus-induced transcription factor activated by a diverse array of extracellular signals. Annu. Rev. Biochem. 68, 821-861. doi: 10.1146/annurev.biochem.68.1.821

Shi, J. (2015). Regulatory networks between neurotrophins and miRNAs in brain diseases and cancers. Acta Pharmacol. Sin. 36, 149-157. doi: 10.1038/aps. 2014.135

Shruthi, S., Sumitha, R., Varghese, A. M., Ashok, S., Chandrasekhar Sagar, B. K., Sathyaprabha, T. N., et al. (2017). Brain-derived neurotrophic factor facilitates functional recovery from ALS-cerebral spinal fluid-induced neurodegenerative changes in the NSC-34 motor neuron cell line. Neurodegener Dis. 17, 44-58. doi: 10.1159/000447559

Silani, V., Braga, M., Cardin, V., and Scarlato, G. (2001). The pathogenesis of ALS: implications for treatment strategies. Neurol. Neurochir. Pol. 35, 25-39.

Sirabella, R., Valsecchi, V., Anzilotti, S., Cuomo, O., Vinciguerra, A., Cepparulo, P., et al. (2018). Ionic homeostasis maintenance in ALS: focus on new therapeutic targets. Front. Neurosci. 12:510. doi: 10.3389/fnins.2018.00510

Slack, S. E., and Thompson, S. W. (2002). Brain-derived neurotrophic factor induces NMDA receptor 1 phosphorylation in rat spinal cord. Neuroreport 13, 1967-1970. doi: 10.1097/00001756-200210280-00027

Song, M., Martinowich, K., and Lee, F. S. (2017). BDNF at the synapse: why location matters. Mol. Psychiatry 22, 1370-1375. doi: 10.1038/mp.2017.144

Song, R. S., Massenburg, B., Wenderski, W., Jayaraman, V., Thompson, L., and Neves, S. R. (2013). ERK regulation of phosphodiesterase 4 enhances dopaminestimulated AMPA receptor membrane insertion. Proc. Natl. Acad. Sci. U.S.A. 110, 15437-15442. doi: 10.1073/pnas.1311783110 
Spalloni, A., Geracitano, R., Berretta, N., Sgobio, C., Bernardi, G., Mercuri, N. B., et al. (2006). Molecular and synaptic changes in the hippocampus underlying superior spatial abilities in pre-symptomatic G93A+/+ mice overexpressing the human $\mathrm{Cu} / \mathrm{Zn}$ superoxide dismutase (Gly93 -> ALA) mutation. Exp. Neurol. 197, 505-514. doi: 10.1016/j.expneurol.2005.10.014

Stevens, B., Allen, N. J., Vazquez, L. E., Howell, G. R., Christopherson, K. S., Nouri, N., et al. (2007). The classical complement cascade mediates CNS synapse elimination. Cell 131, 1164-1178. doi: 10.1016/j.cell.2007.10.036

Stoilov, P., Castren, E., and Stamm, S. (2002). Analysis of the human TrkB gene genomic organization reveals novel TrkB isoforms, unusual gene length, and splicing mechanism. Biochem. Biophys. Res. Commun. 290, 1054-1065. doi: 10.1006/bbrc.2001.6301

Tao, X., Finkbeiner, S., Arnold, D. B., Shaywitz, A. J., and Greenberg, M. E. (1998). $\mathrm{Ca} 2+$ influx regulates BDNF transcription by a CREB family transcription factor-dependent mechanism. Neuron 20, 709-726. doi: 10.1016/s08966273(00)81010-7

Tebano, M. T., Martire, A., Chiodi, V., Ferrante, A., and Popoli, P. (2010). Role of adenosine $\mathrm{A}(2 \mathrm{~A})$ receptors in modulating synaptic functions and brain levels of BDNF: a possible key mechanism in the pathophysiology of Huntington's disease. ScientificWorldJournal 10, 1768-1782. doi: 10.1100/tsw.2010.164

Tebano, M. T., Martire, A., Potenza, R. L., Gro, C., Pepponi, R., Armida, M., et al. (2008). Adenosine $\mathrm{A}(2 \mathrm{~A})$ receptors are required for normal BDNF levels and BDNF-induced potentiation of synaptic transmission in the mouse hippocampus. J. Neurochem. 104, 279-286.

Tejeda, G. S., and Diaz-Guerra, M. (2017). Integral characterization of defective $\mathrm{BDNF} / \mathrm{TrkB}$ signalling in neurological and psychiatric disorders leads the way to new therapies. Int. J. Mol. Sci. 18, 268. doi: 10.3390/ijms18020268

Teng, H. K., Teng, K. K., Lee, R., Wright, S., Tevar, S., Almeida, R. D., et al. (2005). ProBDNF induces neuronal apoptosis via activation of a receptor complex of p75NTR and sortilin. J. Neurosci. 25, 5455-5463. doi: 10.1523/jneurosci.512304.2005

The BDNF Study Group Phase III, (1999). A controlled trial of recombinant methionyl human BDNF in ALS: the BDNF study group phase III. Neurology $52,1427-1433$.

Tongiorgi, E. (2008). Activity-dependent expression of brain-derived neurotrophic factor in dendrites: facts and open questions. Neurosci. Res. 61, 335-346. doi: 10.1016/j.neures.2008.04.013

Trang, T., Beggs, S., and Salter, M. W. (2011). Brain-derived neurotrophic factor from microglia: a molecular substrate for neuropathic pain. Neuron Glia Biol. 7, 99-108. doi: 10.1017/S1740925X12000087

Tsai, T., Klausmeyer, A., Conrad, R., Gottschling, C., Leo, M., Faissner, A., et al. (2013). 7,8-Dihydroxyflavone leads to survival of cultured embryonic motoneurons by activating intracellular signaling pathways. Mol. Cell Neurosci. 56, 18-28. doi: 10.1016/j.mcn.2013.02.007

Tucker, K., and Fadool, D. A. (2002). Neurotrophin modulation of voltagegated potassium channels in rat through $\operatorname{TrkB}$ receptors is time and sensory experience dependent. J. Physiol. 542, 413-429. doi: 10.1113/jphysiol.2002. 017376

Turner, M. R., Hardiman, O., Benatar, M., Brooks, B. R., Chio, A., De Carvalho, M., et al. (2013). Controversies and priorities in amyotrophic lateral sclerosis. Lancet Neurol. 12, 310-322. doi: 10.1016/S1474-4422(13)70036-X

Turrigiano, G. (2012). Homeostatic synaptic plasticity: local and global mechanisms for stabilizing neuronal function. Cold Spring Harb. Perspect. Biol. 4:a005736. doi: 10.1101/cshperspect.a005736
Tyler, W. J., and Pozzo-Miller, L. D. (2001). BDNF enhances quantal neurotransmitter release and increases the number of docked vesicles at the active zones of hippocampal excitatory synapses. J. Neurosci. 21, 4249-4258. doi: 10.1523/jneurosci.21-12-04249.2001

Van Den Bosch, L., Van Damme, P., Bogaert, E., and Robberecht, W. (2006). The role of excitotoxicity in the pathogenesis of amyotrophic lateral sclerosis. Biochim. Biophys. Acta 1762, 1068-1082.

van Zundert, B., Peuscher, M. H., Hynynen, M., Chen, A., Neve, R. L., Brown, R. H., et al. (2008). Neonatal neuronal circuitry shows hyperexcitable disturbance in a mouse model of the adult-onset neurodegenerative disease amyotrophic lateral sclerosis. J. Neurosci. 28, 10864-10874. doi: 10.1523/JNEUROSCI.134008.2008

Vidaurre, O. G., Gascon, S., Deogracias, R., Sobrado, M., Cuadrado, E., Montaner, J., et al. (2012). Imbalance of neurotrophin receptor isoforms TrkB-FL/TrkB-T1 induces neuronal death in excitotoxicity. Cell Death Dis. 3:e256. doi: 10.1038/ cddis. 2011.143

Vilar, M., and Mira, H. (2016). Regulation of neurogenesis by neurotrophins during adulthood: expected and unexpected roles. Front. Neurosci. 10:26. doi: 10.3389/ fnins.2016.00026

Wheaton, M. W., Salamone, A. R., Mosnik, D. M., Mcdonald, R. O., Appel, S. H., Schmolck, H. I., et al. (2007). Cognitive impairment in familial ALS. Neurology 69, 1411-1417.

Yacoubian, T. A., and Lo, D. C. (2000). Truncated and full-length TrkB receptors regulate distinct modes of dendritic growth. Nat. Neurosci. 3, 342-349. doi: $10.1038 / 73911$

Yamashita, N., and Kuruvilla, R. (2016). Neurotrophin signaling endosomes: biogenesis, regulation, and functions. Curr. Opin. Neurobiol. 39, 139-145. doi: 10.1016/j.conb.2016.06.004

Yanpallewar, S. U., Barrick, C. A., Buckley, H., Becker, J., and Tessarollo, L. (2012). Deletion of the BDNF truncated receptor TrkB.T1 delays disease onset in a mouse model of amyotrophic lateral sclerosis. PLoS One 7:e39946. doi: 10.1371/ journal.pone.0039946

Zhai, J., Zhou, W., Li, J., Hayworth, C. R., Zhang, L., Misawa, H., et al. (2011). The in vivo contribution of motor neuron TrkB receptors to mutant SOD1 motor neuron disease. Hum. Mol. Genet. 20, 4116-4131. doi: 10.1093/hmg/ddr335

Zhang, W., Liu, L. Y., and Xu, T. L. (2008). Reduced potassium-chloride co-transporter expression in spinal cord dorsal horn neurons contributes to inflammatory pain hypersensitivity in rats. Neuroscience 152, 502-510. doi: 10.1016/j.neuroscience.2007.12.037

Zheng, F., Zhou, X., Luo, Y., Xiao, H., Wayman, G., and Wang, H. (2011). Regulation of brain-derived neurotrophic factor exon IV transcription through calcium responsive elements in cortical neurons. PLoS One 6:e28441. doi: 10. 1371/journal.pone.0028441

Conflict of Interest Statement: The authors declare that the research was conducted in the absence of any commercial or financial relationships that could be construed as a potential conflict of interest.

Copyright (c) 2019 Pradhan, Noakes and Bellingham. This is an open-access article distributed under the terms of the Creative Commons Attribution License (CC BY). The use, distribution or reproduction in other forums is permitted, provided the original author(s) and the copyright owner(s) are credited and that the original publication in this journal is cited, in accordance with accepted academic practice. No use, distribution or reproduction is permitted which does not comply with these terms. 